\title{
Estuaries and Coasts
}

\section{Salt marsh accretion and storm tide variation: An example from a barrier island in the North Sea \\ --Manuscript Draft--}

\begin{tabular}{|c|c|}
\hline Manuscript Number: & ESCO-D-11-00016R2 \\
\hline Keywords: & Salt marsh, accretion rate, geochronology, storm activity, barrier island, Sylt \\
\hline \multicolumn{2}{|l|}{$\begin{array}{l}\text { Corresponding Author Secondary } \\
\text { Information: }\end{array}$} \\
\hline Corresponding Author's Institution: & University of Kiel / Institute of Geography \\
\hline \multicolumn{2}{|l|}{ First Author Secondary Information: } \\
\hline \multirow[t]{5}{*}{ All Authors: } & Mark Schürch, Diploma \\
\hline & John Rapaglia, PhD \\
\hline & Volker Liebetrau, PhD \\
\hline & Athanasios Vafeidis, Junior Professor \\
\hline & Karsten Reise, Professor \\
\hline \multicolumn{2}{|l|}{ All Authors Secondary Information: } \\
\hline
\end{tabular}


COVER LETTER - SUBMISSION OF REVISED MANUSCRIPT

Kiel, October 27, 2011

\section{Subject: SUBMISSION OF REVISED MANUSCRIPT:}

"Salt marsh accretion and storm tide variation: An example from a barrier island in the North Sea"

Dear Editor(s),

I would like to thank you for the evaluation of the revised manuscript (first submitted on the $11^{\text {th }}$ of January 2011). We have addressed all the minor modifications suggested by the 2 reviewers and have revised the manuscript accordingly.

Based on the suggestions of reviewer \#1, we revised figure 1 and all other figures by increasing their resolution and incorporating the other suggested modifications. Furthermore, we converted the bulk density numbers to SI-units and double-checked all the numbers throughout the manuscript. We are confident that all numbers are now correct.

Addressing the comments of reviewer \#2, we rewrote the abstract, including the methods of how we constructed the presented geochronology and focusing on historical responses of salt marsh accretion rates in relation to storm pattern rather than future predictions. We also made some corrections within the manuscript removing speculative parts about future developments. Concerning the estimation of autocompaction, we included a rationale for only using the upper $5 \mathrm{~cm}$ of the cores for analysis within the "Methods" section.

The additional modifications suggested by the reviewers have further improved the manuscript and we are confident that the paper is now ready for publication.

Please find enclosed the revised manuscript, together with the detailed answers to the comments of the 2 reviewers.

Sincererly yours

Mark Schürch 


\section{Reply to reviewer \#1}

Please note: Replies in violet are the most recent replies to the $2^{\text {nd }}$ review of reviewer \#1.

\section{Comments from review \#1}

Study site

Line 81. Are these coordinates right? As far as I can tell from Google Earth, this is a site in west Jutland in Denmark??

Coordinates were corrected to $54^{\circ} 54^{\prime} \mathrm{N}, 008^{\circ} 20^{\prime} \mathrm{E}$.

Please state the coordinates for sampling site. You need to be more precise. Now we are on Sild, but in the middle of a town. Include the seconds as well.

Coordinates were changed to $54^{\circ} 47^{\prime} 18^{\prime}$ ' $\mathrm{N} / 008^{\circ} 17^{\prime} 30^{\prime}$ ' $\mathrm{E}$. This corresponds to a location in the middle of the investigated salt marsh.

Figure 1. This is a poor figure. The top figure seems to be out of proportions.

The coordinate system of the top figure was changed from WGS 1984 to ETRS 1989 UTM, this will hopefully help the reader understand the figure.

This is still a poor figure. The resolution seems to be too low (at least in my copy). In the bottom right figure I can't find neither the Path/Road nor the Veg. not specified. Either delete these two legends or find a way to make them clear on the figure.

We increased the resolution of figure 1 and all other figures to 300 dpi. We deleted the "Road / Path" entry from the legend and made the "Vegetation not specified" more visible in the figure.

\section{New comments for review \#2}

\section{S 12 RESULTS}

Please use SI units and state the dry bulk density in $\mathrm{kg} \mathrm{m}^{-3}$

We changed the units of bulk density from $\mathrm{kg} \mathrm{dm}^{-3}$ to $\mathrm{kg} \mathrm{m}^{-3}$. We also changed the respective numbers in figure 3.

$S 12$ line 289. I think there is a typo here, the dry bulk density cannot be $9.39 \mathrm{~kg} \mathrm{dm}^{-3}$ (pure solid quartz is around $2.6 \mathrm{~kg} \mathrm{dm}^{-3}$ ).

The value was corrected to $939 \mathrm{~kg} \mathrm{~m}^{-3}$.

S 12 Line 299. The same, the DBD is too high at 5-6 $\mathrm{kg} \mathrm{dm}^{-3}$

The values were corrected to $500-600 \mathrm{~kg} \mathrm{~m}^{-3}$.

$S 12$ line 293. The same $\left(3.25 \& 6.56 \mathrm{~kg} \mathrm{dm}^{-3}\right)$

The values were corrected to 325 and $656 \mathrm{~kg} \mathrm{~m}^{-3}$.

$S 13$ line 294. The same (4.5-5 $\left.\mathrm{kg} \mathrm{dm}^{-3}\right)$

The values were corrected to $450-500 \mathrm{~kg} \mathrm{~m}^{-3}$. 
S 13 line 304-308. I think you mean decrease instead of increase in the upper $5 \mathrm{~cm}$. Is the decrease significant?

Since all other bulk density values are reported from a top-down perspective, we would rather use the same method here. This means that it is an increase with depth.

The increase can be represented by a logarithmic regression at a significance level of $p<0.02$. The paragraph was reworded respectively: "The increase of bulk density within the uppermost $5 \mathrm{~cm}$ of core S1 was found to fit the logarithmic model (equation 6; $R^{2}=0.97, p<0.02$ ), which is considered as evidence for autocompaction. Model parameters $A$ and $B$ were estimated to be 0.0879 and 0.3791 , respectively. The autocompaction rate during the growth of the salt marsh therefore averages $1 \mathrm{~mm}$ yr-1."

As far as I can tell from fig 3, all densities are below $2 \mathrm{~kg} \mathrm{dm}^{-3}$, and most of the fine grained material is around $0.5 \mathrm{~kg} \mathrm{dm}^{-3}$.

In fact, most fine grained material is around $500 \mathrm{~kg} \mathrm{~m}^{-3}$ in cores $\mathrm{S} 2$ and $\mathrm{S} 3$. However this is different in S1, where bulk density increases with depth from about 325 to $656 \mathrm{~kg} \mathrm{~m}^{-3}$. This should also be detectable in figure 3 .

$S 16$ line 370. The acc rate of $1.5-1.8 \mathrm{~mm} / \mathrm{yr}$ does not correspond with the numbers in Table 1 (1 $-1.2 \mathrm{~mm} / \mathrm{yr}$ )

The numbers in the text were changed to $1-1.2 \mathrm{~kg} \mathrm{~m}^{-3}$.

\section{IN GENEREL, THE AUTHORS SHOULD DOBBLE CHECK ALL NUMBERS IN THE MANUSCRIPT.}

All numbers were double checked: Besides a few minor changes, we have corrected the value for the mean accretion rate in $\mathrm{S} 3$ from $4 \mathrm{~mm} \mathrm{yr}^{-1}$ to $2.5 \mathrm{~mm} \mathrm{yr}^{-1}$ and the threshold for the inundation depth from $26 \mathrm{~cm}$ to $18 \mathrm{~cm}$.

We are sure that ALL number are correct now.

S 19 line 444. Don't you mean S1 and S2. As far as I can tell S3 does not contain Cs137.

We do mean core S2 and S3. The fact that S3 does not show a 137Cs peak supports the dating since this suggests that the marsh started to develop after 1986. A respective explanation was added: "The absence of a peak in core S3 also supports what we can observe in the aerial photographs, as well as the ${ }^{210} \mathrm{~Pb}$ dating suggesting that the marsh development started after 1988."

Figures: you seem to have exchanged fig 5 and fig 6.

Revised as suggested.

Fig 12: you need a label on the $x$-axis

We added the following label for the x-axis: "Storm water level ( $m$ above NN)". 


\section{Replies to reviewer \#2}

Reviewer \#2: I have read the article by Schuerch et al., in which they use sedimentary geochronologies to examine how marshes in the Wadden Sea have responded to climate variability over the past century, and how the might respond to future changes in climate over the next century. Overall, this is a pretty good paper. However, I think it needs one substantial change and several more minor ones before it can be accepted for final publication.

Thank you for reviewing the paper and for your very valuable feedback. We revised our paper according to your suggestions and are happy to see that the paper has considerably gained from these changes.

\section{Major changes:}

The most important changes that are needed are with respect to the authors' analysis of how these marshes will respond to future changes in climate. In their abstract, they write, "Future development of low-lying marsh zones will therefore be controlled by mean high water levels, while upper marsh accretion rates will be controlled by storm activity. We suggest that climate change has a higher impact on the marsh zonation rather than on marsh survival." This statement is too broad.

This sentence was worded: "Beyond the impact of sea level rise, we conclude that for high inundation heights occurring in lower marsh zones, the mean strength of storms is predominantly affecting marsh accretion, while for low inundation heights, occurring in higher marsh zones, the frequency of storms is the dominant driver for marsh accretion."

In this paper the authors have mostly measured processes that occur along the vertical axis, and have not really considered what can happen along the horizontal plane. (Aside from a brief examination of aerial photographs). In other words, most of their data is core data, and not a detailed analysis of spatial change, such as might be done with a GIS. The authors don't seem to consider whether increased storm activity could increase shoreface erosion, and how a decreasing marsh width might impact interior regions of the marsh. This problem needs to be corrected.

We are aware of the fact that less consideration has been given to lateral marsh development within our study. In order to emphasize this limitation we added the following phrases at the beginning of the "Influence of storm on accretion" ("Discussion"): "The analysis presented in this study focuses on the historical vertical development of a single salt marsh. It is shown that an increase in storminess positively correlates with marsh accretion rates. While many authors have focused on the destructive, erosional influence of storms on salt marshes (e.g. Callaghan et al. 2010, Mariotti and Fagherazzi 2010, van de Koppel et al. 2005), our methods are not able to reproduce the lateral marsh development and their implications on accretion processes, but rather the vertical marsh accretion."

I would suggest that the authors

1) focus more on their analysis of the past response of marshes to storms and sea level change, which is very well done, rather than speculate on future changes, which is more tenuous.

We removed the paragraph "Future marsh development". As you mention, it is indeed not sufficiently supported by the available data. Consequently we also reworded the respective paragraph in the "Conclusions" focusing more on what we could observe rather than what we expect for the future.

2) recognize the difference between things that are measured in a core and things that occur in the lateral environment. 
The concept of the critical inundation height found in our data has spatial implications, since inundation depth is higher in the low marsh zone than in the high marsh zone. We reworded the respective phrase in the abstract (as described above) to make clear that this is the only spatial implication that we are suggesting.

\section{Minor changes:}

Abstract: The abstract needs a bit of rewording. The authors should avoid the passive voice whenever possible. Also, the authors could include a few more specifics- such as by noting how the geochronologies were constructed.

The abstract was reworded. We replaced the formulations with passive voice and added the three methods employed for the reconstruction of historic marsh accretion.

Lines 35-36. The Kirwan citations are not right citations. It would be better to cite Redfield (1972) or Orson (1985).

Revised as suggested.

Line 54. The authors have a comma after the $K+G$ paper, but I think they mean to have a period.

The comma follows the introductory clause "While ..." and separates it from the main clause. We think that the comma is grammatically correct.

Line 79 - an elsewhere. The authors refer to figures using lowercase letters. I would prefer to see the word figure capitalized and abbreviated-as "Fig. 1." However, I will defer to the editorial staff for on any final determination of the article's style.

Revised as suggested.

Line 126. The authors should prove, or provide data, indicating that compaction was negligible.

The following sentence, summarizing the data that underlies this statement is added: "Compaction during core collection was measured in situ as the difference between the measures from the top of the PVC-tube to the salt marsh surface outside and inside the core. This difference was found vary between 2 and $4 \%$ of the core length (in all three cores) and was therefore assumed to be negligible."

Lines 170-172. Why was autocompaction only investigated in the top $5 \mathrm{~cm}$. Certainly it can happen anywhere in the core. This seems weird and either needs to be explained in more detail or the analysis should be conducted on the entire core. Even if Bartholdy (2010) present a method to use this, the rationale for using their method must be explained in sufficient detail in the paper for that rationale to stand alone.

We added an explanation why we employed the method following the mentioned sentence: "[...], since variability of bulk density triggered by changes of grain size and organic carbon content in the lower parts of the core was too large to derive reliable estimates for autocompaction."

Line 214. De Groot is not the right citation. This was understood long before 2009. You might try Compton (1923) instead.

Revised as suggested.

Line 280 . I believe this sentence should read, "Fine grained sediments are?." 
Revised as suggested.

Line 284-308. The authors need to be more careful about the number of significant figures attached to the bulk density values. Are 4 significant figures really appropriate.

All bulk density estimates were rounded to no decimal figures (applying the SI unit $\mathrm{kg} \mathrm{m}^{-3}$ ).

Also, I am not used to seeing bulk densities listed as $\mathrm{kg} / \mathrm{dm} 3$, and instead would prefer to see them as $\mathrm{g} / \mathrm{cm} 3$ or $\mathrm{kg} / \mathrm{m} 3$ unless the authors have a compelling reason to do otherwise.

The unit of bulk density was changed to $\mathrm{kg} / \mathrm{m}^{3}$.

Line 326 (and elsewhere). For excess $210 \mathrm{~Pb} \mathrm{I}$ am used to seeing the subscript XS rather than exc, and I would prefer to see that used - unless the authors have a compelling reason to do otherwise.

Revised as suggested.

Line 516. General comment: I very much like the authors analysis of storm influence on marsh accretion. It would be interesting to hear some discussion as to whether the authors think this is due to the positive shift in the NAO as some (e.g. Hurrell et al., 2001) or whether this is an imprint of an acceleration in global sea level rise rates as others (e.g. Kolker et al., 2010), have noted.

We are aware of the close relationship between storminess and the NAO index suggested by some authors, but we could not find this relationship in our data. We think that a positive shift in the NAO index could positively influence salt marsh accretion. However our data does not prove this hypothesis sufficiently to discuss it within the paper. We currently conduct further investigations on separating the different climatic influences on salt marsh accretion by means of modeling.

Line 588. The authors write, " No confident predictions for the future development of storm patterns are available at the moment." This sentence is a bit poorly constructed and should be rewritten.

As stated earlier this paragraph was removed altogether.

Figure 8. The horizontal lines in this figure are kind of ugly. I think that this happens when you make figures in MS excel. There is a way to get rid of these lines, and this should be done.

Revised as suggested (all figures were compiled in Matlab). 


\section{Salt marsh accretion and storm tide variation:}

2 An example from a barrier island in the North

\section{Sea}

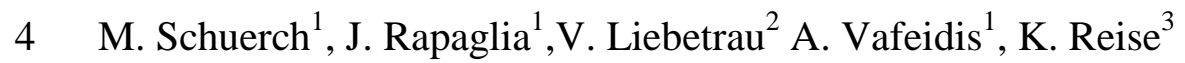

$5{ }^{1}$ University of Kiel, Institute of Geography, "The Future Ocean" Excellence

6 Cluster, Germany

$7{ }^{2}$ Leibniz Institute of Marine Science, IFM-GEOMAR, "The Future Ocean"

8 Excellence Cluster, Kiel, Germany

$9{ }^{3}$ Alfred Wegner Institute for Polar and Marine Research, Waddenseastation Sylt,

10 Germany

11 Corresponding address: Mark Schürch, schuerch@geographie.uni-kiel.de, +49 4318805641

12 (phone), +49 4318804658 (fax)

\section{ABSTRACT}

15 We reconstruct past accretion rates of a salt marsh on the island of Sylt, Germany, using

16 measurements of the radioisotopes ${ }^{210} \mathrm{~Pb}$ and ${ }^{137} \mathrm{Cs}$, as well as historical aerial photographs.

17 Results from three cores indicate accretion rates varying between 1 and $16 \mathrm{~mm} \mathrm{yr}^{-1}$. Comparisons

18 with tide gauge data show that high accretion rates during the 1980's and 1990's coincide with

19 periods of increased storm activity. We identify a critical inundation height of $18 \mathrm{~cm}$ below which

20 the strength of a storm seems to positively influence salt marsh accretion rates, and above which

21 the frequency of storms becomes the major factor. Beyond the impact of sea level rise, we

22 conclude that for high inundation heights occurring in lower marsh zones, the mean strength of

23 storms is predominantly affecting marsh accretion, while for low inundation heights, occurring in

24 higher marsh zones, the frequency of storms is the dominant driver for marsh accretion.

26 KEYWORDS

27 Salt marsh, accretion rate, geochronology, storm activity, barrier island, Sylt 


\section{INTRODUCTION}

29 Coastal salt marshes in the Wadden Sea (southeastern North Sea) are abundant

30 leeward of the East Frisian and North Frisian barrier islands as well as in front of

31 the dike system on the Dutch-German-Danish North Sea coast. Salt marshes serve

32 as coastal protection structures by reducing the impact of waves on the upper

33 shoreline (e.g. Möller, 2006) and as important habitats for specialized plants and

34 animals including migratory and breeding waterfowl, and breeding birds (Reise et

35 al., 2010). The existence of salt marshes is critically dependent on how fast

36 sediment accretes relative to sea level rise (Orson et al., 1985; Redfield, 1972).

37 Salt marshes are complex coastal features, governed by various physical and

38 biological processes creating a system that exists in dynamic equilibrium with

39 relative sea level rise (RSLR; Allen, 2000). Salt marsh accretion, defined as the

40 vertical growth of the marsh, occurs when organic and/or inorganic sediments are

41 deposited onto the marsh during inundation (allochthonous growth), as well as

42 when salt marsh plants grow and decompose (autochthonous growth; Dijkema,

43 1987; Kolker et al., 2009). Projected acceleration in SLR, however, may outpace

44 accretion rates in the future, if an insufficient amount of material is deposited on

45 the marsh surface (Kirwan and Temmerman, 2009; Orson et al., 1985). Several

46 investigators studied marsh response to mean sea level rise (French, 1993; Kirwan

47 and Temmerman, 2009; e.g. Orson et al., 1985; Reed, 1995), others investigated

48 the influence of tidal range on salt marsh accretion (e.g. Chmura et al., 2001;

49 Harrison and Bloom, 1977; Kirwan and Guntenspergen, 2010), but relatively little

50 literature is available discussing the impact of non-tidal short-term sea level

51 variations on salt marsh accretion (Bartholdy et al., 2004; French, 2006; Kolker et

52 al., 2009; Temmerman et al., 2003b). While it is a widespread assumption that 
53 macrotidal environments are more resilient against SLR than microtidal

54 environments (Kirwan and Guntenspergen, 2010), Allen (2000) and Kolker et al.

55 (2009) conclude that marsh accretion is dominated by wind-induced (short-term)

56 sea level variations in microtidal, and by SLR-induced long-term sea level

57 variations in macrotidal environments. It remains unclear how wind-induced sea

58 level variations enhance the resilience of the salt marsh, and in particular, whether

59 many minor storms are more effective in triggering accretion than a few major

60 storms. This is noteworthy as certain studies suggest that the storm activity in the

61 German Bight has increased in recent years and will most likely increase in the

62 near future leading to more frequent storm surges and/or higher storm surge water

63 levels (Beniston et al., 2007; Fischer-Bruns et al., 2005; Rockel and Woth, 2007;

64 von Storch and Weisse, 2008; Woth et al., 2006).

65 The goal of this work is to reconstruct the development of a back-barrier salt

66 marsh on the island of Sylt, Germany, by using both ${ }^{210} \mathrm{~Pb}$ and ${ }^{137} \mathrm{Cs}$ as

67 geochronometers. ${ }^{210} \mathrm{~Pb}$ and ${ }^{137} \mathrm{Cs}$ are often used for studying soil and sediment

68 processes (Armentano and Woodwell, 1975; Delaune et al., 1978; Goodbred and

69 Kuehl, 1998; He and Walling, 1996b; Kolker et al., 2009). These data will be

70 combined with information gathered from aerial photographs. We report how the

71 marsh has been growing during the last decades and compare accretion rates with

72 historical tide gauge data in order to infer how storm activity affects marsh

73 accretion and its resilience against accelerated SLR.

\section{Study site}

75 The island of Sylt is located in the German Wadden Sea $\left(54^{\circ} 47^{\prime} 18^{\prime}\right.$ 'N,

$76008^{\circ} 17^{\prime} 30^{\prime}$ 'E), in the south-eastern North Sea (Fig. 1). Its core is made of

77 Pleistocene protruding outcrops. About 7000 years B.P., during a period of SLR 
78 deceleration (Milne et al., 2005), local sea level reached its current position and

79 sandy spits were formed north and south of the original Pleistocene outcrop

80 (Ahrendt and Thiede, 2001). Sylt is an elongated barrier island with a total area of

$8199 \mathrm{~km}^{2}$ extending $40 \mathrm{~km}$ from north to south and ranging from 1 to $13 \mathrm{~km}$ in

82 width (Kelletat, 1992). The western coastline is characterized by extensive

83 beaches and dunes, and, due to a relatively steep offshore elevation gradient, it is

84 exposed to highly energetic wave activity from the North Sea (Ahrendt and

85 Köster, 1998). The sheltered eastern coastline is fringed by extensive tidal flats.

86 Salt marshes are found in the transition zone from dunes to tidal flats and have a

87 total area of approximately $5 \mathrm{~km}^{2}$ (TMAP - The Trilateral Monitoring and

88 Assessment Program 2006).

89 The mean tidal range, as of 2010, at the nearby tide gauge Hörnum Hafen is

$902.06 \mathrm{~m}$ (WSA - Wasser- und Schifffahrtsamt Tönning, 2007), varying from $1.8 \mathrm{~m}$

91 at neap tide to $2.3 \mathrm{~m}$ at spring tide (BSH - Bundesamt für Seeschifffahrt und

92 Hydrographie, 2008). Tidal range has constantly increased in the Wadden Sea,

93 including the Hörnumtief, since 1955 (Jensen and Mudersbach, 2004).

94 The immediate study area is located in the southern third of Sylt between the

95 villages of Rantum and Hörnum, and is characterized by the typical morphology

96 of a barrier island. A transect from the open North Sea to the tidal flats is marked

97 by a sequence of beaches, dunes, and salt marshes (Hildebrandt et al., 1993).

98 These dunes developed a dense grass and scrub vegetation and became stable, as a

99 consequence of intense planting activities since 1864 (ALW - Amt für Land- und

100 Wasserwirtschaft Husum, 1997). The area of the investigated marsh is about

$1010.3 \mathrm{~km}^{2}$, with a length of about $2 \mathrm{~km}$ and a width ranging from $80 \mathrm{~m}$ to $280 \mathrm{~m}$.

102 The salt marsh itself has a typical zonation ranging from pioneer marsh vegetation

103 at the seaward edge to high marsh vegetation close to the foot of the dunes (Fig. 
104 1). The pioneer marsh is dominated by the introduced cordgrass Spartina anglica,

105 the low marsh zone is dominated by Atriplex portulacoides, and the high marsh

106 zone by Juncus gerardi and Elymus athericus. The vegetation is not grazed by

107 domestic livestock.

108 The elevation of the salt marsh ranges from about 0.7 to $1.5 \mathrm{~m}$ above $\mathrm{NN}$ (NN:

109 German reference datum; Fig. 2), while the mean high water level (MHW) is at

110 about $1 \mathrm{~m}$ (NN; WSA - Wasser- und Schifffahrtsamt Tönning, 2007). The

111 topography of the marsh is rather homogeneous, with a small marsh cliff (10-

$11220 \mathrm{~cm}$ height) at the transition from pioneer to low marsh (Fig. 2). It is therefore

113 assumed possible to reconstruct the historic evolution of this salt marsh by

114 analyzing one transect only.

\section{METHODS AND ANALYSIS}

\section{Sample collection and preparation}

117 Three marsh cores were collected on 22 January 2009 using PVC tubes with an

118 inner diameter of $11.8 \mathrm{~cm}$. Cores were collected on a shore-normal transect,

119 within the three dominant vegetation zones (Fig. 1, 2) and had a length of about

$120 \quad 50-70 \mathrm{~cm} . \mathrm{S} 3$, the most seaward core, was collected about $30 \mathrm{~m}$ from the seaward

121 edge of the pioneer marsh, while S2 and S1 were located about $60 \mathrm{~m}$ and $110 \mathrm{~m}$

122 inland from the seaward edge respectively (Fig. 2). The large diameter of the tube

123 was chosen in order to reduce possible compaction of the soil during collection, as

124 well as to amass a large volume of material for accurate analysis. Compaction

125 during core collection was measured in situ as the difference between the

126 measures from the top of the PVC-tube to the salt marsh surface outside and 
127 inside the core. This difference was found to vary between 2 and $4 \%$ of the core

128 length (in all three cores) and was therefore assumed to be negligible.

129 The transect where the cores were taken was leveled by hand using a dumpy level

130 on a tripod. The height of the (seaward) starting point was determined by

131 comparison of measured flooding and HW times between the starting point and

132 the tide gauge in Hörnum Hafen. Elevations of the 3 core locations, as of today,

133 are $0.94 \mathrm{~m}(\mathrm{~S} 3), 1.34 \mathrm{~m}(\mathrm{~S} 2)$ and $1.44 \mathrm{~m}(\mathrm{~S} 1)$ above $\mathrm{NN}$ (Fig. 2). S3 is the only

134 core location that is regularly inundated, while S1 and S2 are only inundated

135 during storm tides.

136 After extraction, the cores were sliced into layers with a thickness of $1-5 \mathrm{~cm}$. The

137 thickness of the layers progressively increased towards the bottom of the core.

138 The sediment was freeze-dried and ground manually in order to disintegrate the

139 conglomerates of sediment. The ground material was filled into Petri dishes with a

140 diameter of $52 \mathrm{~mm}$ and embedded into epoxy resin, which prevented ${ }^{222} \mathrm{Rn}$ from

141 degassing. The dry weight of the aliquots embedded for radiometric analysis

142 ranged from 17.25 to 43.44 g. Samples were allowed to sit for at least 3 weeks in

143 order to reach equilibrium between ${ }^{226} \mathrm{Ra}$ and ${ }^{214} \mathrm{Bi}$ before analysis.

144 Sedimentology: Grain size, organic carbon content, and bulk density

145 Salt marsh sediment was analyzed for grain size, organic carbon content, and bulk

146 density in order to derive the depths of the base layer and for calculation of

147 radioisotope inventories. Grain size measurements were conducted using laser

148 diffractometry (Malvren Mastersizer 2000). Although this method is supposed to

149 measure grain sizes ranging from 0.02 to $2000 \mu \mathrm{m}$ (Malvern Instruments Ldt,

150 2010), gradually increasing uncertainties in the coarser spectrum of grain sizes

151 were observed during pre-measurements. Therefore, the sediment was sieved at 
$1521000 \mu \mathrm{m}$ before the measurements. The preparation of the samples included the

153 destruction of organic carbon, using $\mathrm{H}_{2} \mathrm{O}_{2}$, and iron if necessary, using sodium

154 bicarbonate, sodium citrate, and sodium dithionite. The measurements were

155 conducted at obscuration rates between 5 and $30 \%$.

156 The organic carbon content was measured using the element analyzer Euro EA,

157 which performs $\mathrm{C} / \mathrm{N}$ analysis. The organic carbon is oxydized in the system and

158 escapes as $\mathrm{CO}_{2}$ into a gas chromatographer where total $\mathrm{C}$ (and $\mathrm{N}$ ) content is 159 determined.

160 The bulk density ( $\rho$ ) was indirectly calculated from the organic carbon and the

161 water content $\left(\mathrm{O}_{\mathrm{C}}\right.$ and $\left.\mathrm{W}\right)$ in the samples as not enough sample material was

162 available in the upper layers for direct measurement. Assuming a constant density

163 for water $\left(\rho_{\mathrm{W}}=1.02 \mathrm{~g} \mathrm{~cm}^{-3}\right)$ and for mineral and organic matter $\left(\rho_{\mathrm{M}}=2.6 \mathrm{~g} \mathrm{~cm}^{-3}\right.$,

$164 \rho_{\mathrm{O}}=1.2 \mathrm{~g} \mathrm{~cm}^{-3}$ respectively), the bulk density was calculated using the following

165 formula (Kolker et al., 2009):

$$
\rho=\frac{1-W}{\frac{W}{\rho_{W}}+\frac{1-W}{\left(1-O_{C} * \rho_{M}\right)+\left(O_{C} * \rho_{O}\right)}}
$$

167 Additional measurements on dry bulk density and relative water content were 168 conducted on cores extracted on the 18 May 2011 in order to validate these bulk

169 density calculations. It was shown that the results of the model fit the measured 170 data $\left(\mathrm{R}^{2}=0.98, \mathrm{p}<0.01\right)$.

\section{Assessment of autocompaction}

172 Bulk density calculations were used for the assessment of autocompaction within

173 the cores S1, S2, and S3. Bulk densities within the uppermost $5 \mathrm{~cm}$ of the salt

174 marsh cores were investigated for autocompaction (Bartholdy et al., 2010), since 
175 variability of bulk density triggered by changes of grain size and organic carbon

176 content in the lower parts of the core was too large to derive reliable estimates for

177 autocompaction. A logarithmic curve (equation 6) was fitted through the

178 calculated bulk density data (BDD) within the uppermost $5 \mathrm{~cm}$.

$$
B D D=A^{*} \ln (z)+B
$$

180 where A and B are constants to be optimized and $\mathrm{z}$ is the depth of the respective

181 salt marsh layer.

182 If the model was found to significantly represent the bulk density data $(\mathrm{p}<0.05)$,

183 autocompaction was included into the calculation of accretion rates by

184 decompacting the core. Decompaction was performed by calculating the thickness

185 of a layer in depth $\mathrm{z}\left(\mathrm{T}_{\mathrm{z}}\right)$ to the time when it was deposited using the inverse

186 version of the equation presented by Williams et al. (2003):

$$
T_{z}=\frac{B D D_{z}}{B D D_{0}} * T_{0}
$$

188 where $\mathrm{BDD}_{0}$ and $\mathrm{T}_{0}$ are the bulk dry density and the thickness of today's surface

189 layer, respectively.

\section{Radiometric measurements}

$191{ }^{137} \mathrm{Cs}\left(\mathrm{t}_{1 / 2}=30.2\right.$ years $)$ is a product of nuclear fission, and is highly particle

192 reactive (He and Walling, 1996b). In Europe, it is marked by two main periods of

193 atmospheric fallout (1963 and 1986) producing two useful marker horizons

194 (Delaune et al., 1978; Kirchner and Ehlers, 1998; Pedersen et al., 2007). The ${ }^{137}$ Cs

195 peak around 1963 is produced by a series of tests of nuclear bombs during the

196 1950's and 1960's, while the 1986-peak is a result of the nuclear disaster in

197 Chernobyl. Some authors have found an additional ${ }^{137} \mathrm{Cs}$ signal in cores taken

198 along the North and the Baltic Sea, peaking between 1974 and 1977 (Andersen et 
199 al., 2000; Kunzendorf et al., 1998). However given the low initial activity and the

20030 year half-life of ${ }^{137} \mathrm{Cs}$, these activities are probably below detection limits

201 today. ${ }^{210} \mathrm{~Pb}\left(\mathrm{t}_{1 / 2}=22.3\right.$ years $)$, on the other hand, is constantly being supplied from

202 the atmosphere via the decay of its grandparent nuclide ${ }^{222} \mathrm{Rn}$ (Koide et al., 1972;

203 Walling et al., 2003). This continuous deposition makes ${ }^{210} \mathrm{~Pb}$ an excellent

204 geochronometer for deriving accretion rates in coastal salt marshes (Appleby and

205 Oldfield, 1978; Appleby and Oldfield, 1983; Bartholdy et al., 2004; Bellucci et

206 al., 2007; Kirchner and Ehlers, 1998).

207 A low-background coaxial $\mathrm{Ge}(\mathrm{Li})$ detector was employed to measure total gamma208 ray activity of ${ }^{210} \mathrm{~Pb},{ }^{226} \mathrm{Ra}$, and ${ }^{137} \mathrm{Cs}$. It is a non-destructive counting method that 209 allows simultaneous measurement of all three radionuclides (Nikulina, 2008).

210 Measurement of ${ }^{226} \mathrm{Ra}$ is necessary, because it is a proxy for supported ${ }^{210} \mathrm{~Pb}$. The

211 analysis was conducted by the 'Laboratory for Radioisotopes' in Goettingen,

212 Germany. ${ }^{210} \mathrm{~Pb}$ was measured via its gamma peak at $46.6 \mathrm{keV},{ }^{137} \mathrm{Cs}$ via its peak

213 at $661.7 \mathrm{keV}$, and ${ }^{226} \mathrm{Ra}$ via the peaks of its granddaughters ${ }^{214} \mathrm{~Pb}$ and ${ }^{214} \mathrm{Bi}$ at

$214352 \mathrm{keV}$ and $609.3 \mathrm{keV} / 1120.3 \mathrm{keV}$ respectively. The measurement time for all

215 samples was 250,000 seconds.

\section{Errors / Detection limit}

217 Errors generally increase towards the low energy gamma ray spectrum, since the

218 background radiation is elevated as a consequence of the Compton effect of

219 higher energetic radionuclides (Compton, 1923). Meanwhile for higher energy

220 spectra, the background radiation decreases continuously. For ${ }^{210} \mathrm{~Pb}$ that is

221 measured at $46.6 \mathrm{keV}$ (very low energy) this is of particular importance, since the

222 background radiation within the sample may be elevated above the ${ }^{210} \mathrm{~Pb}$ activity

223 of the soil sample, resulting in measurements below detection limit. 
224 Another source of error for radiometric measurements is the background radiation

225 of the environment, which is quantified by measuring a parallel blank sample and

226 minimized by increasing the sample volume as well as the counting time.

227 The combined "internal" and environmental background radiation at $46.6 \mathrm{keV}$ is

228 therefore higher than the activity measured for ${ }^{226} \mathrm{Ra}$ in higher energy spectra and

229 detection limits can be included into the analysis as maximum values for ${ }^{210} \mathrm{~Pb}$

230 activities.

\section{$231 \quad$ Dating model}

232 The constant rate of supply model (CRS) is employed for the dating of sediment

233 characterized by variations of initial concentrations (Appleby and Oldfield, 1978;

234 Appleby and Oldfield, 1983). It is therefore useful in study sites with irregular

235 inundation, where accretion rates strongly vary with time. This model allows for

236 the calculation of the age of the sediment by using radioisotope inventories

237 (Appleby and Oldfield, 1978; Kolker et al., 2009).

238 Due to the relative elevation of the core locations within the tidal frame (Fig. 2),

239 irregular inundation occurs during storm surges, negating the assumption that

240 accretion rates are constant over time. Therefore the CRS model was used for this

241 study.

\section{Aerial photographs}

243 Aerial photographs of the investigated area, provided by the Landesbetrieb für

244 Küstenschutz, Nationalpark und Meeresschutz Schleswig-Holstein (LKN-SH),

245 were utilized in order to analyze the historic extension of the salt marsh during the

246 last century and to verify the radiometric measurements. Photographs were

247 available from 1937, 1958, 1988, 1999, 2003, and 2007. After georeferencing the 
248 pictures and overlaying the core locations, visual interpretation was performed in

249 order to classify the core location into the categories 'marsh' and 'no marsh'.

250 Hydrological data

251 Annual data about mean sea level (MSL) were calculated from annual mean high

252 water (MHW) and mean low water (MLW) levels (Hofstede 2010: pers. comm.).

253 Storm frequency and storm intensity were aggregated from the high water levels,

254 collected for every tidal cycle between 1938 and 2007 (Wahl 2010: pers. comm.,

255 Wahl et al. 2011). Eustatic sea level rise was included into the analysis as an

256 underlying trend that was removed from the original dataset before storm

257 parameterization was conducted. Global SLR data, presented by Church and

258 White (2011), were used for that purpose due to a lack of reliable estimates of

259 local eustatic SLR.

260 Storm activity was parameterized by storm frequency, defined as the number of

261 tides above a certain storm level, and by storm intensity, defined as the mean

262 height of these storm tides. For storm parameterization, we used these definitions

263 in order to ensure that storm intensity is statistically independent from storm

264 frequency. Mean sea level in turn was calculated as a function of MHW and

265 MLW (Wahl et al., 2010).

266 Mean values of storm intensity and frequency data were aggregated for all years

267 in which an estimate for accretion rate was available, using a moving average

268 filter. Taking into account an expected error and temporal resolution of the dating

269 of the sediment layers, the window size was chosen to be 5 years. 


\section{Analysis of storm-related salt marsh accretion}

271 One of the main objectives of this study is to investigate the influence of storm

272 frequency and storm intensity on the observed accretion rates. Multiple linear

273 regression analysis was employed to assess how much of the variation within the

274 accretion rate time series can be explained by one of these parameters. This

275 analysis was carried out by including all high water levels that flooded the marsh

276 from 1938-2007. By gradually increasing the storm level, and therefore excluding

277 the low inundation events, we investigated how different high water levels were

278 influencing accretion rates in the past. The standardized coefficients ( $ß$ ) of the

279 multiple linear regressions, as well as the p-values were compared for the different

280 storm levels.

\section{RESULTS}

282 Grain size analysis and organic carbon content, and bulk density

283 In each of the cores a fine-grained upper layer is underlain by layers comprised of

284 mainly coarse-grained sediments. The transition zone in core S1 is very distinct

285 and fine-grained sediments are not present below a depth of about $10 \mathrm{~cm}$ (Fig. 3).

286 In contrast, the transition zones in cores S2 and S3 are more gradual. Fine-grained

287 sediment is, in fact, present throughout the entire core S2 (Fig. 3).

288 Bulk densities reproduce this pattern of fine-grained sediments on top of a coarse-

289 grained base layer by increasing at the interfaces of salt marsh sediments and the

290 sandy base layer (Fig. 3). In core S1, a clear increase of bulk density is observed

291 at a depth of about $10 \mathrm{~cm}$, reaching $1574 \mathrm{~kg} \mathrm{~m}^{-3}$. The high bulk density of

$2921469 \mathrm{~kg} \mathrm{~m}^{-3}$ at the depth of $4.5 \mathrm{~cm}$ is considered as an outlier and was therefore

293 excluded from the analysis. Instead, the average from the neighboring upper and 
294 lower layers was employed. The increase in S2 is more gradual and constant, with

295 a maximum bulk density of $939 \mathrm{~kg} \mathrm{dm}^{-3}$ at $27 \mathrm{~cm}$. In core $\mathrm{S} 3$, a considerable

296 increase in bulk density is observed at a depth of about $5 \mathrm{~cm}$, with a maximum

297 value of $1591 \mathrm{~kg} \mathrm{~m}^{-3}$. Within the silty salt marsh sediments bulk densities in cores

298 S2 and S3 do not significantly increase, mostly varying between 500 and

$299600 \mathrm{~kg} \mathrm{~m}^{-3}$. In core $\mathrm{S} 1$ a significant increase from 326 to $656 \mathrm{~kg} \mathrm{~m}^{-3}$ within the

300 uppermost $6 \mathrm{~cm}$ is observed, bulk density then decreases to $450-500 \mathrm{~kg} \mathrm{~m}^{-3}$ in the

301 lower silty layers.

302 Salt marsh sediments are characterized by fine-grained material with high organic

303 content, which allows for visual and experimental determination of the thickness

304 of the marsh layer deposited on top of the sandy base. Herein, the base of the

305 marsh can clearly be identified in cores S1 and S3 at $8.5 \mathrm{~cm}$ and $4.5 \mathrm{~cm}$

306 respectively; whereas it is not as clear in core S2 (Fig. 3). The fine-grained

307 fraction rapidly decreases at $21 \mathrm{~cm}$, but increases at 23 and $27 \mathrm{~cm}$ again. Although

308 high fractions of sand at depths of 21 and $25 \mathrm{~cm}$ are found, marsh development

309 seems to have started at a depth of about $27 \mathrm{~cm}$.

310 The increase of bulk density within the uppermost $5 \mathrm{~cm}$ of core $\mathrm{S} 1$ was found to

311 fit the logarithmic model (equation $6 ; \mathrm{R}^{2}=0.97, \mathrm{p}<0.02$ ), which is considered as

312 evidence for autocompaction. Model parameters A and B were estimated to be

3130.0879 and 0.3791 , respectively. The autocompaction rate during the growth of

314 the salt marsh therefore averages $1 \mathrm{~mm} \mathrm{yr}^{-1}$.

\section{Aerial photographs}

316 The first photograph available, taken in 1937 (Fig. 4a), provides strong evidence

317 for the presence of marsh at locations S1 and S2, however no marsh is yet present

318 at location S3. A sand bar seems to have formed between the seaward edge of the 
319 marsh and the adjacent tidal flat. At the landward edge of the marsh sand appears

320 to be transported onto the marsh surface. However, in the following photograph

321 from 1958 (Fig. 4b), sand transport onto the marsh at the landward edge seems to

322 be less visible than in 1937; meanwhile the sand bar at the seaward edge has

323 developed further offshore. Recent photographs from 1988 and 1995 (Fig. 4c+d)

324 do not show considerable changes of the marsh extension towards the land, but do

325 indicate a seaward expansion. In 1988 (Fig. 4c), core location S3 is found to be in

326 a channel between the developing pioneer marsh and the mature main part of the

327 marsh. The photo from 1995 (Fig. 4d), shows that the channel appears to be

328 closed and covered by pioneer marsh vegetation. Marsh development at core

329 location S3 is, therefore, estimated to have started between 1988 and 1995.

\section{Radioisotope data}

$331 \quad{ }^{210} \mathrm{~Pb}$ data

332 All three depth profiles of excess ${ }^{210} \mathrm{~Pb}\left({ }^{210} \mathrm{~Pb}\right.$ Xs $)$ generally decrease as expected

333 (Fig. 5). Large variations are found in the surface concentrations, with the highest

334 activity $\left(232 \mathrm{~Bq} \mathrm{~kg}^{-1}\right.$ in $\left.1.5 \mathrm{~cm}\right)$ in core $\mathrm{S} 1$. Distinct peaks are found at a depth of

$3351.5 \mathrm{~cm}$ in all three cores.

336 In core $\mathrm{S} 1$ a slow decrease is observed, due to relatively high activities

$337\left(116 \mathrm{~Bq} \mathrm{~kg}^{-1}, 112 \mathrm{~Bq} \mathrm{~kg}^{-1}\right)$ at depths of 4.5 and $5.5 \mathrm{~cm}$. Activities below $10 \mathrm{~cm}$ are

338 all less than the the detection limit and therefore less than $12.6 \mathrm{~Bq} \mathrm{~kg}^{-1}$ (Fig. 5).

339 The initial decrease in S2 is much greater, and influenced by low activity at

$3404.5 \mathrm{~cm}$ (below detection limit of $9.5 \mathrm{~Bq} \mathrm{~kg}^{-1}$ ). Activities below $4.5 \mathrm{~cm}$ decrease

341 slower, eventually resulting in activities below the detection limit for all depths

342 lower than $17 \mathrm{~cm}$ (Fig. 5). In core $\mathrm{S} 3,{ }^{210} \mathrm{~Pb}$ Xs also quickly decreases within the 
343 upper $7 \mathrm{~cm}$ from $129 \mathrm{~Bq} \mathrm{~kg}^{-1}$ at $1.5 \mathrm{~cm}$ to less than $2.6 \mathrm{~Bq} \mathrm{~kg}^{-1}$ at $7.5 \mathrm{~cm} .{ }^{210} \mathrm{~Pb}_{\mathrm{XS}}$

344 activities at lower depths are all below the detection limit (Fig. 5).

$345 \mathrm{As}{ }^{210} \mathrm{~Pb}$ activities in the sandy substrate of the cores $\mathrm{S} 1$ and $\mathrm{S} 3$ are all below the

346 detection limit, normalization for grain size and organic carbon content of these

347 activities is impossible. In core S2, where the fraction of fine grained, highly

348 organic sediment is rather constant within salt marsh layers, normalization is not

349 necessary.

$350 \quad{ }^{137}$ Cs data

$351{ }^{137}$ Cs peaks are found in cores $\mathrm{S} 1$ and S2. In core S3, no ${ }^{137} \mathrm{Cs}$ peak was found. S1

352 is characterized by a major peak at a depth of $5.5 \mathrm{~cm}\left(267 \mathrm{~Bq} \mathrm{~kg}^{-1}\right)$ and a minor

353 peak at $8.5 \mathrm{~cm} \mathrm{(38} \mathrm{Bq} \mathrm{kg}{ }^{-1}$; Fig. 6). ${ }^{137} \mathrm{Cs}$ appears to decrease towards zero at

354 about $15 \mathrm{~cm}$, although it should be considered that the sediment below $10 \mathrm{~cm}$ is

355 very coarse and the effect of coarse grained sediment might reduce the ${ }^{137} \mathrm{Cs}-$

356 activity (He and Walling, 1996a). In core S2 the situation is clearer: 2 peaks are

357 found in depths of $5.5 \mathrm{~cm}\left(64 \mathrm{~Bq} \mathrm{~kg}^{-1}\right)$ and $17 \mathrm{~cm}\left(52 \mathrm{~Bq} \mathrm{~kg}^{-1}\right)$; we note that the

358 upper peak's activity is significantly lower than the activity in S1 (Fig. 6). The

$359{ }^{137}$ Cs activity in core S3 is missing a distinct peak and has a very low activity

$360\left(<1 \mathrm{~Bq} \mathrm{~kg}^{-1}\right)$ in the sandy base layer. Finer sediments in the upper layers are

361 marked by a slight increase in activity up to $8 \mathrm{~Bq} \mathrm{~kg}^{-1}$ (Fig. 6).

362 Age of base layer

363 The age of the marsh and the mean accretion rates were determined by

364 radioisotope dating $\left({ }^{210} \mathrm{~Pb}\right)$ and compared with aerial photographs (table 1$)$. The

365 base layer at core location $\mathrm{S} 1$ is found at a depth of about $8.5 \mathrm{~cm}$ (Fig. 2, 3).

366 Aerial photographs show that the marsh was present in 1937. However, analysis 
367 of ${ }^{210} \mathrm{~Pb}$ data does not support this finding, suggesting the marsh to be younger.

368 Several ${ }^{210} \mathrm{~Pb}$ data in core $\mathrm{S} 1$ and $\mathrm{S} 3$ are below the detection limit due to a

369 relatively high baseline activity in these samples. Since the detection limit is

370 considered as a maximum activity and allows for activities within the range of

371 zero to the detection limit, the original error range needs to be extended. Therefore

372 the year when the base layer was deposited (according to ${ }^{210} \mathrm{~Pb}$ dating) is

373 calculated to be between 1925 ( \pm 5 years) and 1955 ( \pm 5 years) (table 1$)$. Utilizing

374 these dates and the aerial photographic evidence we conclude that the marsh

375 started to develop between 1925 ( \pm 5 years) and 1937, resulting in a mean

376 accretion rate between 1 and $1.2 \mathrm{~mm} \mathrm{yr}^{-1}$. In core S2 the base layer is found at a

377 depth of $27 \mathrm{~cm}$ (Fig. 2, 3). ${ }^{210} \mathrm{~Pb}$ dating suggests that this layer was deposited in

3781915 ( \pm 5 years). The aerial photograph of 1937 confirms the existence of the

379 marsh at that time. Therefore, the mean accretion rate for core location S2 is

380 estimated to be $2.8 \mathrm{~mm} \mathrm{yr}^{-1}$ (table 1). S3 has a marsh layer that is only $4.5 \mathrm{~cm}$

381 thick (Fig. 2, 3), but no ${ }^{210} \mathrm{~Pb}$ measurement is available for the base layer at that

382 depth. Meanwhile the sample at $3.5 \mathrm{~cm}$ is calculated to be deposited in 1996,

383 suggesting a mean accretion rate of $2.5 \mathrm{~mm} \mathrm{yr}^{-1}$. Aerial photographs indicate the

384 beginning of the pioneer (Spartina-) marsh development between 1988 and 1995.

385 Accretion rates

386 A reliable time series of accretion rates could only be drawn for the core S2,

387 because the marsh layer in S3 is too thin to show significant variations, while

$388{ }^{210} \mathrm{~Pb}$ dating for $\mathrm{S} 1$ resulted in small accretion rates associated with large

389 uncertainties. However, for S1, a general trend towards an increase of accretion

390 rates can be observed from the beginning of the 1960s, resulting in a recent

391 accretion rate between 3 and $3.5 \mathrm{~mm} \mathrm{yr}^{-1}$. Accretion rates for $\mathrm{S} 2$ indicate strong 
392 variations over the last 75 years, ranging from about $1 \mathrm{~mm} \mathrm{yr}^{-1}$ up to $16 \mathrm{~mm} \mathrm{yr}^{-1}$

393 (Fig. 7). No clear trend can be observed, although accretion rates in the 1980's

394 and 1990's seem to be higher. Two distinct peaks are found in 1982 and 1992

395 (according to ${ }^{210} \mathrm{~Pb}$ dating).

396 Hydrology and meteorology

397 Tide gauge data from1938 to 2007 were analyzed for historic trends (Fig. 8) and 398 compared to ${ }^{210} \mathrm{~Pb}$-derived marsh elevations (Fig. 9). It is shown that the MSL at 399 the tide gauge Hoernum Hafen within that time period rose by about $2.1 \mathrm{~mm} \mathrm{yr}^{-1}$, 400 slightly greater than the global rate of SLR of $1.8 \mathrm{~mm} \mathrm{yr}^{-1}$ during the same period 401 (Church and White, 2011). The rise of MSL was accompanied by a mean increase 402 of the MHW of about $4 \mathrm{~mm} \mathrm{yr}^{-1}$, while the MLW did not change significantly.

403 The increase of both MHW and MSL was observed to accelerate since about the 404 early 1980's. This corresponds to data analyzed by Wahl et al. (2010), who further 405 pointed out that SLR rates during the last 10-15 years within the German Bight 406 were higher than the global average, as reported by Church et al. (2008). The

407 frequency of storm floods was analyzed based on their definition given by the 408 German Maritime and Hydrographic Agency (BSH), where storm floods are 409 water levels exceeding $1.5 \mathrm{~m}$ above MHW. Considering that the averaged yearly 410 MHW from 1938 to 2007 is $0.9 \mathrm{~m}$ above $\mathrm{NN}$, this corresponds to a storm level of

$4112.4 \mathrm{~m} \mathrm{NN}$. It was shown that storm frequency experienced a linear increase of 4120.06 events $\mathrm{yr}^{-1}$, while 1984 and 1990 were marked by the greatest number of 413 storms with 10 and 11 events, respectively. During the same period the intensity

414 of these storms did not significantly change.

415 As MHW increased rapidly within the last 50 years, salt marsh growth was not 416 able to keep pace with this rise. An average of 2.6 and $1.3 \mathrm{~mm} \mathrm{yr}^{-1}$ was lost 
417 relative to MHW at core location S1 and S2 respectively. Core location S3 was

418 observed to accrete at a rate of $2.5 \mathrm{~mm} \mathrm{yr}^{-1}$ since 1996. Meanwhile, during that

419 period, MHW strongly increased with a rate of $11 \mathrm{~mm} \mathrm{yr}^{-1}$ (Fig. 9). Marsh

420 elevation of $\mathrm{S} 2$ relative to MSL, on the other hand increased by $0.7 \mathrm{~mm} \mathrm{yr}^{-1}$, while

$421 \mathrm{~S} 1$ decreased by $0.6 \mathrm{~mm} \mathrm{yr}^{-1}$ (Fig. 9).

\section{Influence of storm frequency and intensity on accretion rates}

423 The marsh at core location S2 floods when the water level reaches $134 \mathrm{~cm}(\mathrm{NN}$;

424 Fig. 2). Multiple linear regression analysis shows that storm intensity $(\beta=0.88$,

$425 \mathrm{p}<0.01)$ describes accretion rates better than storm frequency $(\beta=0.06, p>0.1)$,

426 when considering all inundation events (Fig. 10). However, with an increasing

427 maximum storm level there is a decreasing influence of the storm intensity,

428 whereas the influence of storm frequency gradually increases. At a storm level of

$429260 \mathrm{~cm}$, for example, storm frequency gives a $\beta$ of $0.86(\mathrm{p}<0.01)$, while storm

430 intensity cannot explain accretion rates significantly $(ß=0.04, p>0.1$; Fig. 11$)$. It

431 appears that the storm level of $152 \mathrm{~cm}$ (equals an inundation height of $18 \mathrm{~cm}$ at

432 core location S2) is the turning point where the influence of storm frequency

433 becomes statistically significant $(\mathrm{p}<0.1)$; meanwhile the influence of storm

434 intensity progressively diminishes (Fig. 12).

\section{DISCUSSION}

$436{ }^{210} \mathrm{~Pb}$ geochronologies were used at three salt marsh levels (i) to determine the age

437 of the marsh and to reconstruct its evolution, (ii) to assess temporal variations of

438 accretion rates at all three core locations, and (iii) to identify the hydrological

439 parameters influencing marsh accretion. 


\section{Support for accretion rate calculation}

441 In contrast to the continuous deposition of ${ }^{210} \mathrm{~Pb}$ on the marsh surface, ${ }^{137} \mathrm{Cs}$ serves

442 as a marker horizon that can be used to calculate mean accretion rates in between

443 the years 1963, 1986, and 2009, when the cores were extracted. It is, therefore, an

444 additional independent geochronometer that allows for comparison with the ${ }^{210} \mathrm{~Pb}$

445 dating method, but not for derivation of higher resolved temporal accretion rates.

446 Both the 1963 and 1986 peaks were found in cores S1 and S2. In core S1, ${ }^{137}$ Cs

447 overestimates accretion rates compared to the ${ }^{210} \mathrm{~Pb}$ data and the aerial photograph

448 of 1937 (Fig. 9). It seems that ${ }^{137} \mathrm{Cs}$ has been transported further down in the soil

449 column, although we are not certain of the mechanism. A very good agreement

450 between the three methods $\left({ }^{137} \mathrm{Cs},{ }^{210} \mathrm{~Pb}\right.$, and aerial photographs $)$ is found in core

$451 \mathrm{~S} 2$ and in core $\mathrm{S} 3 .{ }^{137} \mathrm{Cs}$ in core $\mathrm{S} 2$ shows two distinct peaks at depths of $5.5 \mathrm{~cm}$

452 and $17 \mathrm{~cm} .{ }^{210} \mathrm{~Pb}$ dating is supported by these peaks; the layers at depths of $5.5 \mathrm{~cm}$

453 and $17 \mathrm{~cm}$ were estimated to be deposited in 1992 and 1961 respectively (Fig. 9).

454 The absence of a peak in core S3 also supports what we can observe in the aerial

455 photographs, as well as the ${ }^{210} \mathrm{~Pb}$ dating suggesting that the marsh development

456 started after 1988.

457 Grain size data also support the ${ }^{210} \mathrm{~Pb}$ dating in core $\mathrm{S} 2$ to a certain degree. Two

458 layers $(5.5 \mathrm{~cm}$ and $9.5 \mathrm{~cm})$ show an elevated fraction of coarse-grained sediments

459 in comparison to the other layers (Fig. 3). ${ }^{210} \mathrm{~Pb}$ dating calculates that these layers

460 were deposited in 1992 ( \pm 5 years) and 1985 ( \pm 5 years). In 1990, the highest

461 number of storms occurred during the last 70 years (Fig. 8), 2 of which were

462 among the 5 most severe storm surges (measured at Hörnum Hafen) in recorded

463 history. Meanwhile, the year 1984 was marked by the second most frequent storm

464 events during the last 70 years (Fig. 8). We expect that the higher energy of 
465 storms allows for the transport of coarser-grained materials onto the marsh by

466 both waves and currents.

\section{Mean accretion rates}

468 The spatial pattern of mean accretion rates shows a decrease from the low marsh

469 towards the inner marsh (table 1). This is a typical spatial phenomenon observed

470 on many marshes by various authors (Bartholdy et al., 2004; Cahoon and Reed,

471 1995; French and Spencer, 1993; Pethick, 1981; Temmerman et al., 2003a).

472 Meanwhile the mean accretion rate for the pioneer marsh zone is lower than the

473 one in the low marsh zone. Resuspension of sediment during the early stage of the

474 marsh development could be the reason for this pattern. The measured accretion

475 rates generally compare well with mean accretion rates measured on the peninsula

476 of Skallingen, where Bartholdy et al. (2004) found the accretion rate on the

477 Skallingen marsh to vary between $2 \mathrm{~mm} \mathrm{yr}^{-1}$ on the inner marsh and $4 \mathrm{~mm} \mathrm{yr}^{-1}$ on

478 the outer marsh. Measurements of Kirchner and Ehlers (1998) in the eastern part

479 of Sylt, however, have shown much higher accretion rates between $5.8 \mathrm{~mm} \mathrm{yr}^{-1}$

480 and $15.2 \mathrm{~mm} \mathrm{yr}^{-1}$, but grain sizes in this section of Sylt are much finer, indicating

481 different hydrodynamic conditions favoring settling of sediment.

\section{Temporal variations of accretion rates}

483 S2 shows strong temporal variations of accretion with a period of higher rates

484 found during the 1980s and 1990s including two distinct peaks in 1982 and 1992

485 and a rapid decrease in accretion rates during the last 20 years. This pattern

486 strongly resembles the periods of high storm activity (Fig. 10, 11). Although

487 temporal variations of accretion rates in S1 should only be considered as an

488 approximation, a trend towards increasing accretion rates to current values 
489 between 3-3.5 $\mathrm{mm} \mathrm{yr}^{-1}$ is observed. The few data points that exist for S3 show a

490 constant accretion rate of $2.5 \mathrm{~mm} \mathrm{yr}^{-1}$.

491 Accretion rates at core location S2 during calm periods seem to lie close to the

492 rates of eustatic SLR (Fig. 10, 11), while, during stormy years, accretion rates are

493 much higher than SLR. This behavior shows the importance of storms for the

494 resilience of salt marshes towards eustatic SLR. Even though, accretion rates

495 during calm years are still sufficiently high, a considerable decrease in storminess

496 would lower the marsh elevation and possibly affect the marsh zonation.

\section{Historic development of the marsh}

498 Using the data presented in the previous section it is possible to reconstruct the

499 historic evolution of the marsh: Marsh development at our study site seems to

500 have started after about 1915. Prior to marsh development, we assume a bare

501 sandy beach slope at that location. The age of the base layer at core location S2

502 indicates that marsh development started during a period of rapidly increasing

503 MHW and MLW levels (Jensen and Mudersbach, 2004; Wahl et al., 2010).

504 Increasing inundation frequencies may have triggered the development of pioneer

505 marsh vegetation, such as Salicornia and Suaeda, probably sheltered by a seaward

506 sandy ridge. At some point, the sandy ridge at the seaward edge moved offshore

507 and a cliff arose due to increased hydrodynamics caused by more frequent

508 inundation events. As a consequence, a channel developed in front of the marsh,

509 which probably acted as a tidal channel, building up levees at the landward and

510 seaward side (Pedersen and Bartholdy, 2007). According to the aerial photograph

511 in 1988, the pioneer marsh started to develop on top of the sand bar and slowly

512 spread towards the cliff at the marsh edge, stabilizing the latter. Decreased

513 hydrodynamics in the vicinity of the sand bar, a constantly low MLW-level, and a 
514 spread of the invasive species Spartina anglica after 1987 (Loebl et al., 2006),

515 may have triggered that process. Today the cliff is located far inside the marsh

516 and the pioneer marsh seems to expand further onto the tidal flat and accrete faster

517 than MSLR.

518 The inner part of the marsh accreted with the slowest overall accretion rate. While

519 the base layer is approximately $30 \mathrm{~cm}$ above the base layer in the central part of

520 the marsh, marsh development started between 1925 and 1937. During the first

521 few decades of growth, aerial photographs indicate that considerable amounts of

522 sand may have been blown onto this part of the marsh; although, accretion rates

523 were too low to detect significant temporal variations. The topography of the

524 marsh platform has been flattened during the last 75 years due to higher accretion

525 rates in the middle of the marsh, than on the landward side of the marsh.

\section{Influence of storms on accretion}

527 The analysis presented in this study focuses on the historical vertical development

528 of a single salt marsh. It is shown that an increase of storminess positively

529 correlates with marsh accretion rates. While many authors have focused on the

530 destructive, erosional influence of storms on salt marshes (e.g. Callaghan et al.

531 2010, Mariotti and Fagherazzi 2010, van de Koppel et al. 2005), our methods are

532 not able to reproduce the lateral marsh development and their implications on

533 accretion processes, but rather the vertical marsh accretion.

534 Vertical accretion (at core location S2) was shown to be closely linked to past

535 storm patterns with accretion rates of up to $16 \mathrm{~mm} \mathrm{yr}^{-1}$ in very stormy years.

536 Linear regression analysis showed that both storm intensity and storm frequency

537 are important factors influencing accretion rates. Storm frequency does not seem

538 to be the driving factor of accretion if storm levels do not rise higher than $18 \mathrm{~cm}$ 
539 above the marsh surface at S2. The importance of frequency greatly increases

540 above this threshold level (Fig. 12). We hypothesize that the presence and the

541 height of the vegetation could be the reason for this threshold.

542 Assuming that the threshold value we found for the core S2 is true for different

543 marsh elevations as well, we can identify two different driving factors for marsh

544 accretion in the lower and the higher parts of the marsh: In the lower marsh zones,

545 where inundation is frequent and usually higher than the vegetation height,

546 accretion rates increase with increasing inundation frequency. Inundation

547 frequency at low elevations, in turn, is highly correlated with the MHW level and

548 possibly caused by SLR. In the higher parts of the marsh, where inundation is less

549 frequent and heights of the inundation are often lower or just slightly higher than

550 the vegetation height, we expect the mean strength of the storms to be more

551 important than the actual number of storms.

552 These findings are especially relevant when considering possible implications on

553 storm related accretion processes. Assuming that more sediment is in suspension

554 when storm water levels are high, the solution of the mass balance equation for

555 incoming and settling sediment (Mudd et al., 2010; Temmerman et al., 2003a)

556 results in an exponential increase of accretion rates with higher storm water levels

557 (Fig. 13; Temmerman et al., 2003a). Considering our results, the effect of storm

558 intensity on salt marsh accretion is suggested to be stronger at low storm water

559 levels than at high storm water levels, resulting in a logarithmic rather than an

560 exponential relationship between storm water levels and accretion rates (Fig. 13).

561 The height at which the logarithmic curve starts to flatten is hypothesized to be

562 connected to the height of the vegetation. Vegetation has a strong effect on flow

563 velocities and the Reynolds number within the vegetation canopy and can

564 therefore influence the flocculation and break-up processes of the sediment in 
565 suspension (Winterwerp, 2002). Low flow velocities within the vegetation canopy

566 could therefore result in larger floc sizes and corresponding settling velocities,

567 while high flow velocities could decrease the floc sizes and decrease the settling

568 velocities of the sediment particles (Bartholomä et al., 2009). This would infer

569 that the depth-averaged settling velocity would decrease with inundation heights

570 that exceed the vegetation height and result in a flatting of the above mentioned

571 curve. We must emphasize that this hypothesis should be further investigated by

572 explicitly examining flocculation processes over salt marsh surfaces during storm

573 events.

\section{Conclusions}

575 In accordance with the available literature, ${ }^{210} \mathrm{~Pb}$ has proven to be a good tool for

576 determination of sediment accretion rates on salt marshes. ${ }^{137} \mathrm{Cs}$ data and aerial

577 photographs independently supported the ${ }^{210} \mathrm{~Pb}$ dating and the derived accretion

578 rates. However, restrictions and limitation of the method can be recognized in

579 core S1 and S3. Based on the results of this study we make the following

580 conclusions:

581 (1) While not always coincident with one another, both storm frequency and

582 intensity seem to affect salt marsh accretion rates. In very stormy years,

583 accretion rates can increase 5-fold above mean value. Frequent and strong

584 storms have shown that they can lead to accretion rates which are higher than

585 MSLR and, therefore are considered as an important factor for the ability of

586 marshes to keep pace with eustatic SLR.

587 (2) We show that eustatic SLR slightly increases accretion rates during calm

588 wind periods, while a surplus of accretion is observed in stormy years,

589 leading to a net increase of marsh elevation relative to mean sea level, 
accompanied by a slight decrease in elevation relative to the more rapidly

$591 \quad$ rising mean tidal high water level.

592 (3) There exists a threshold for inundation depth $(18 \mathrm{~cm})$ on the investigated

593 marsh at which the relative importance of storm frequency and intensity

594 reverses. Storm intensity seems to be the driving factor for high accretion

595 rates below an inundation depth of $18 \mathrm{~cm}$, while storm frequency is more

596 important above this inundation depth. The influence of vegetation is

$597 \quad$ suggested to be the reason for this threshold.

598 (4) The existence of a threshold for inundation depth implies that accretion of

599 higher marsh zones is crucially dependent on the storm intensity, while lower

600 marsh parts rather depend on the development of storm frequency and mean

601 high water level, possibly influenced by a mean sea level rise. The different

602 major driving factors for the marsh zones may lead to changes in marsh

603 zonation, if storm activity and SLR rate change in the future.

604 Further investigation, including short-term measurements of accretion rates during

605 storm events and modeling is necessary to better understand the singular effects of

606 storm intensity, storm frequency, and sea level rise on accretion processes. Also,

607 more marshes in mesotidal environments need to be investigated to test whether a

608 similar critical inundation depth threshold exists elsewhere and the hypothesis of

609 vegetation being responsible can be verified.

\section{Acknowledgements}

611 This project was funded by the Cluster of Excellence 80 “The Future Ocean". The

612 „Future Ocean“ is funded within the framework of the Excellence Initiative by the

613 Deutsche Forschungsgemeinschaft (DFG) on behalf of the German federal and 
614 state governments. Furthermore we would like to thank Anton Eisenhauer for his

615 support and the 'Laboratory for Radioisotopes' in Goettingen for running the

616 radiometric measurements. For their help in the field and during the preparation of

617 the samples, we thank Daniela Arp, Michal Lichter, Tina Geissler, Natalia

618 Zamora, and Claudia Wolff. The hydrological data for the tide gauge Hörnum

619 Hafen were kindly supplied by Thomas Wahl, Jacobus Hofstede, and Gerd

620 Hartwig. We would also like to thank the two anonymous reviewers for their

621 valuable comments, which have helped in improving this manuscript.

\section{References}

623 Ahrendt, K.and R. Köster. 1998. Sylt - einst und jetzt. In Umweltatlas Wattenmeers, Band 1,

624 Nordfriesisches und Dithmarscher Wattenmeer, eds. Nationalpark Schleswig-Holsteinisches

625 Wattenmeer (Tönning) and Umweltbundesamt (Berlin), 38-39. Stuttgart: Eugen Ulmer.

626 Ahrendt, K.and J. Thiede. 2001. Naturräumliche Entwicklung Sylts - Vergangenheit und Zukunft.

627 In Sylt - Klimafolgen für Mensch und Küste, eds. Daschkeit A. and P. Schottes, 69-112. Berlin:

628 Springer.

629 Allen, J. R. L. 2000. Morphodynamics of Holocene salt marshes: a review sketch from the Atlantic

630 and Southern North Sea coasts of Europe. Quaternary Science Reviews 19:1155-1231.

631 ALW - Amt für Land- und Wasserwirtschaft Husum. 1997. Fachplan Küstenschutz Sylt -

632 Fortschreibung. Husum.

633 Andersen, T. J., O. A. Mikkelsen, A. L. Møller, and P. Morten. 2000. Deposition and mixing

634 depths on some European intertidal mudflats based on $210 \mathrm{~Pb}$ and $137 \mathrm{Cs}$ activities. Continental

635 Shelf Research 20:1569-1591.

636 Appleby, P. G.and F. Oldfield. 1978. The calculation of lead-210 dates assuming a constant rate of

637 supply of unsupported $210 \mathrm{~Pb}$ to the sediment. Catena 5:1-8.

638 Appleby, P. G.and F. Oldfield. 1983. The assessment of 210Pb data from sites with varying

639 sediment accumulation rates. Hydrobiologia 103:29-35.

640 Armentano, T. V.and G. M. Woodwell. 1975. Sedimentation Rates in a Long Island Marsh

641 Determined by $210 \mathrm{~Pb}$ Dating. American Society of Limnology and Oceanography 20:452-456. 
642 Bartholdy, J., C. Christiansen, and H. Kunzendorf. 2004. Long term variations in backbarrier salt

643 marsh deposition on the Skallingen peninsula - the Danish Wadden Sea. Marine Geology 203:1-

64421.

645 Bartholdy, J., J. B. T. Pedersen, and A. T. Bartholdy. 2010. Autocompaction of shallow silty salt

646 marsh clay. Sedimentary Geology 223:310-319.

647 Bartholomä, A., A. Kubicki, T. Badewien, and B. Flemming. 2009. Suspended sediment transport

648 in the German Wadden Sea-seasonal variations and extreme events. Ocean Dynamics 59:213-

649225.

650 Bellucci, L. G., M. Frignani, J. K. Cochran, S. Albertazzi, L. Zaggia, G. Cecconi, and H. Hopkins.

651 2007. Pb-210 and Cs-137 as chronometers for salt marsh accretion in the Venice Lagoon - Links to

652 flooding frequency and climate change. Journal of Environmental Radioactivity 97:85-102.

653 Beniston, M., D. Stephenson, O. Christensen, C. Ferro, C. Frei, S. Goyette, K. Halsnaes, T. Holt,

654 K. Jylhä, B. Koffi, J. Palutikof, R. Schöll, T. Semmler, and K. Woth. 2007. Future extreme events

655 in European climate: an exploration of regional climate model projections. Climatic Change 81:71-

65695.

657 BSH - Bundesamt für Seeschifffahrt und Hydrographie. 2008. Gezeitentafeln 2009 - Europäische

658 Gewässer. Hamburg and Rostock: BSH.

659 Cahoon, D. R. and D. J. Reed. 1995. Relationships among Marsh Surface Topography,

660 Hydroperiod, and Soil Accretion in a Deteriorating Louisiana Salt Marsh. Journal of Coastal

661 Research 11:357-369.

662 Callaghan, D. P., T. J. Bouma, P. Klaassen, D. Van der Wal, M. J. F. Stive, and P. M. J. Herman.

663 2010. Hydrodynamic forcing on salt-marsh development: Distinguishing the relative importance

664 of waves and tidal flows. Estuarine, Coastal and Shelf Science 89:73-88.

665 Chmura, G. L., A. Coffey, and R. Crago. 2001. Variation in surface sediment deposition on salt

666 marshes in the Bay of Fundy. Journal of Coastal Research 17:221-227.

667 Church, J. and N. White. 2011. Sea-Level Rise from the Late 19th to the Early 21st Century.

668 Surveys in Geophysics:1-18.

669 Church, J., N. White, T. Aarup, W. Wilson, P. Woodworth, C. Domingues, J. Hunter, and K.

670 Lambeck. 2008. Understanding global sea levels: past, present and future. Sustainability Science $6713: 9-22$. 
672 Compton, A. H. 1923. A Quantum Theory of the Scattering of X-rays by Light Elements. Physical

673 Review 21:483-502.

674 De Groot, A. 2009. Salt-marsh sediment: Natural $\gamma$-radioactivity and spatial patternsthesis,

675 University of Groningen.

676 Delaune, R. D., W. H. Patrick, and R. J. Buresh. 1978. Sedimentation rates determined by 137Cs

677 dating in a rapidly accreting salt marsh. Nature 275:532-533.

678 Dijkema, K. S. 1987. Geography of Salt Marshes in Europe. Zeitschrift Fur Geomorphologie $679 \quad 31: 489-499$.

680 Fischer-Bruns, I., H. Storch, J. González-Rouco, and E. Zorita. 2005. Modelling the variability of 681 midlatitude storm activity on decadal to century time scales. Climate Dynamics 25:461-476.

682 French, J. 2006. Tidal marsh sedimentation and resilience to environmental change: Exploratory

683 modelling of tidal, sea-level and sediment supply forcing in predominantly allochthonous systems.

684 Marine Geology 235:119-136.

685 French, J. R. 1993. Numerical simulation of vertical marsh growth and adjustment to accelerated

686 sea-level rise, North Norfolk, U.K. Earth Surface Processes and Landforms 18:63-81.

687 French, J. R. and T. Spencer. 1993. Dynamics of sedimentation in a tide-dominated backbarrier

688 salt marsh, Norfolk, UK. Marine Geology 110:315-331.

689 Goodbred, S. L.and S. A. Kuehl. 1998. Floodplain processes in the Bengal Basin and the storage

690 of Ganges-Brahmaputra river sediment: an accretion study using 137Cs and 210Pb geochronology.

691 Sedimentary Geology 121:239-258.

692 Harrison, E. Z.and A. L. Bloom. 1977. Sedimentation rates on tidal salt marshes in Connecticut.

693 JOURNAL OF SEDIMENTARY RESEARCH 47:1484-1490.

694 He, Q. and D. E. Walling. 1996a. Interpreting particle size effects in the adsorption of 137Cs and

695 unsupported $210 \mathrm{~Pb}$ by mineral soils and sediments. Journal of Environmental Radioactivity

$69630: 117-137$.

697 He, Q. and D. E. Walling. 1996b. Use of fallout Pb-210 measurements to investigate longer-term

698 rates and pattern of overbank sediment deposition on the floodplains of lowland rivers. Earth

699 Surface Processes and Landforms 21:141-154.

700 Hildebrandt, V., J. Gemperlein, U. Zeltner, and W. Peteresen. 1993. Landesweite Biotopkartierung

701 - Kreis Nordfriesland: Landschaftsentwicklung - Aktuelle Situation - Flächenschutz. Kiel:

702 Landesamt für Naturschutz und Landschaftspflege Schleswig-Holstein. 
703 Jensen, J.and C. Mudersbach. 2004. Zeitliche Änderungen in den Wasserstandszeitreihen an den

704 Deutschen Küsten. In Klimaänderung und Küstenschutz, Conference Proceedings, eds. Gönnert

705 G., H. Grassl, D. Kelletat, H. Kunz, B. Probst, H. von Storch, and J. Sündermann, 115-128.

706 Hamburg.

707 Kelletat, D. 1992. Coastal Erosion and Protection Measures at the German North Sea Coast.

708 Journal of Coastal Research 8:699-711.

709 Kirchner, G. and H. Ehlers. 1998. Sediment Geochronology in Changing Coastal Environments:

710 Potentials and Limitations of the 137Cs and 210Pb Methods. Journal of Coastal Research 14:483-

711492.

712 Kirwan, M. and S. Temmerman. 2009. Coastal marsh response to historical and future sea-level

713 acceleration. Quaternary Science Reviews 28:1801-1808.

714 Kirwan, M. L.and G. R. Guntenspergen. 2010. Influence of tidal range on the stability of coastal

715 marshland. Geophysical Research Letters 115:F02009.

716 Kirwan, M. L., G. R. Guntenspergen, A. D'Alpaos, J. T. Morris, S. M. Mudd, and S. Temmerman.

717 2010. Limits on the adaptability of coastal marshes to rising sea level. Geophysical Research

718 Letters 37:L23401.

719 Koide, M., A. Soutar, and E. D. Goldberg. 1972. Marine geochronology with210Pb. Earth and

720 Planetary Science Letters 14:442-446.

721 Kolker, A. S., S. L. Goodbred Jr, S. Hameed, and J. K. Cochran. 2009. High-resolution records of

722 the response of coastal wetland systems to long-term and short-term sea-level variability.

723 Estuarine, Coastal and Shelf Science 84:493-508.

724 Kunzendorf, H., K.-C. Emeis, and C. Christiansen. 1998. Sedmentation in the Central Baltic Sea

725 as Viewed by Non-Destructive Pb-210-dating Geografisk Tidsskrift 98:1-8.

726 Loebl, M., J. Beusekom, and K. Reise. 2006. Is spread of the neophyte Spartina anglica recently

727 enhanced by increasing temperatures? Aquatic Ecology 40:315-324.

728 Malvern Instruments Ldt. 2010. Mastersizer 2000.

729 http://www.malvern.de/LabGer/products/Mastersizer/MS2000/mastersizer2000.htm. Accessed 31

730 August 2010.

731 Mariotti, G. And S. Fagherazzi. 2010. A numerical model for the coupled long-term evolution of 732 salt marshes and tidal flats. Journal Geophysical Research 115:F01004. 
733 Milne, G. A., A. J. Long, and S. E. Bassett. 2005. Modelling Holocene relative sea-level

734 observations from the Caribbean and South America. Quaternary Science Reviews 24:1183-1202.

735 Möller, I. 2006. Quantifying saltmarsh vegetation and its effect on wave height dissipation:

736 Results from a UK East coast saltmarsh. Estuarine, Coastal and Shelf Science 69:337-351.

737 Mudd, S. M., A. D'Alpaos, and J. T. Morris. 2010. How does vegetation affect sedimentation on

738 tidal marshes? Investigating particle capture and hydrodynamic controls on biologically mediated

739 sedimentation. Journal of Geophysical Research 115:F03029.

740 Nikulina, A. 2008. The imprint of anthropogenic activity versus natural variability in the fjords of

741 Kiel Bight: Evidence from Sediments. PhD thesis, University of Kiel.

742 Orson, R., W. Panageotou, and S. P. Leatherman. 1985. Response of Tidal Salt Marshes of the

743 U.S. Atlantic and Gulf Coasts to Rising Sea Levels. Journal of Coastal Research 1:29-37.

744 Pedersen, J. B. T.and J. Bartholdy. 2007. Exposed salt marsh morphodynamics: An example from

745 the Danish Wadden Sea. Geomorphology 90:115-125.

746 Pedersen, J. B. T., J. Bartholdy, and C. Christiansen. 2007. 137Cs in the Danish Wadden Sea:

747 contrast between tidal flats and salt marshes. Journal of Environmental Radioactivity 97:42-56.

748 Pethick, J. S. 1981. Long-term accretion rates on tidal salt marshes. Journal of Sedimentary

749 Research 51:571-577.

750 Redfield, A. C. 1972. Development of a New England Salt Marsh. Ecological Monographs

$751 \quad 42: 201-237$.

752 Reed, D. J. 1995. The response of coastal marshes to sea-level rise: Survival or submergence?

753 Earth Surface Processes and Landforms 20:39-48.

754 Reise, K., M. Baptist, B. P., N. Dankers, L. Fischer, B. Flemming, A. P. Oost, and C. Smit. 2010.

755 The Wadden Sea - A Universally Outstanding Tidal Wetland. Wadden Sea Ecosystem 29.

756 Common Wadden Sea Secretariat, Wilhelmshaven, Germany: 7-24.

757 Rockel, B. and K. Woth. 2007. Extremes of near-surface wind speed over Europe and their future

758 changes as estimated from an ensemble of RCM simulations. Climatic Change 81:267-280.

759 Temmerman, S., G. Govers, P. Meire, and S. Wartel. 2003a. Modelling long-term tidal marsh

760 growth under changing tidal conditions and suspended sediment concentrations, Scheldt estuary,

761 Belgium. Marine Geology 193:151-169. 
762 Temmerman, S., G. Govers, S. Wartel, and P. Meire. 2003b. Spatial and temporal factors

763 controlling short-term sedimentation in a salt and freshwater tidal marsh, Scheldt estuary,

764 Belgium, SW Netherlands. Earth Surface Processes and Landforms 28:739-755.

765 The Trilateral Monitoring and Assessment Program - TMAP. 2006. Ubgkal07: Topographie DK

766 und SH. Nationalpark Schleswig-Holsteinisches Wattenmeer. http://www.waddensea-

767 secretariat.org/TMAP/Data-Unit/Data.html. Accessed 20 November 2008

768 van de Koppel, J., D. van der Wal, J. P. Bakker, and P. M. J. Herman. 2005. Self-organization and

769 vegetation collapse in salt marsh ecosystems. American Naturalist 165:E1-E12.

770 von Storch, H.and R. Weisse. 2008. Regional storm climate and related marine hazards in the

771 Northeast Atlantic. In Climate Extremes and Society, eds. Diaz H. F. and R. J. Murnane, 54-73.

772 Cambridge: Cambridge University Press.

773 Wahl, T., J. Jensen, and T. Frank. 2010. On analysing sea level rise in the German Bight since

774 1844. Natural Hazards and Earth System Sciences 10:171-179.

775 Walling, D. E., A. L. Collins, and H. M. Sichingabula. 2003. Using unsupported lead-210

776 measurements to investigate soil erosion and sediment delivery in a small Zambian catchment.

777 Geomorphology 52:193-213.

778 Williams, H. 2003. Modeling Shallow Autocompaction in Coastal Marshes Using Cesium-137

779 Fallout: Preliminary Results from the Trinity River Estuary, Texas. Journal of Coastal Research

$780 \quad 19: 180-188$.

781 Winterwerp, J. C. 2002. On the flocculation and settling velocity of estuarine mud. Continental

782 Shelf Research 22:1339-1360.

783 Woth, K., R. Weisse, and H. von Storch. 2006. Climate change and North Sea storm surge

784 extremes: an ensemble study of storm surge extremes expected in a changed climate projected by

785 four different regional climate models. Ocean Dynamics 56:3-15.

786 WSA - Wasser- und Schifffahrtsamt Tönning. 2007. Wasserstandsinformationen: Hörnum/Sylt.

787 http://www.wsv.de/wsa-toe/service/wasserstandinfo/index.html. Accessed 27 August 2010. 


\section{TABLES}

790 Table 1: Ages of base layers and mean sedimentation rates: Comparison of ${ }^{210} \mathrm{~Pb}$ datings with

791 information from aerial photographs.

\begin{tabular}{|l|l|l|l|l|}
\hline Core & $\begin{array}{l}\text { Depth of } \\
\text { name }\end{array}$ & $\begin{array}{l}\text { Age of base layer } \\
\mathbf{( 2 1 0} \mathbf{P b})\end{array}$ & $\begin{array}{l}\text { Age of base layer } \\
\text { (aerial photographs) }\end{array}$ & rate (mm/year) \\
\hline S1 & $8.5 \mathrm{~cm}$ & $1925-1955$ & $<1937$ & $1-1.2$ \\
\hline S2 & 27 & 1915 & $<1937$ & 2.8 \\
\hline S3 & $4.5 \mathrm{~cm}$ & No measurement & $1988-1995$ & $2.5($ since 1996$)$ \\
\hline
\end{tabular}

\section{FIGURE LEGENDS}

793 Fig. 1: The study area is located in the southeastern North Sea (cell 1), in the southern part of the

794 island of Sylt (cell 2). The cores were taken on a transect in three dominant vegetation zones,

795 indicated by points (cell 3).

796 Fig. 2: Topographic profile and marsh zonation of the investigated salt marsh. Core locations and

797 the sandy base layer are indicated by triangles and a dashed line respectively.

798 Fig. 3: Grain size composition (\%) and bulk density calculations $\left(\mathrm{kg} \mathrm{m}^{-3}\right)$, as described in equation

7995 , for all 3 cores and all depths $(\mathrm{cm})$ that were measured. Grain size composition is depicted in the

800 bar graph and bulk density by the line graph. The depth of the sandy base layer is indicated by the

801 dashes line.

$802 \quad$ Fig 4: Aerial photographs of the investigated salt marsh from 1937 (a), 1958 (b), 1988 (c), and

8031995 (d). Dark colours indicate vegetated areas. Bright colours indicate sand. Source:

804 Landesbetrieb für Küstenschutz, Nationalpark und Meeresschutz Schleswig-Holstein (LKN-SH)

805 Fig. 5: Excess ${ }^{210} \mathrm{~Pb}\left(\mathrm{~Bq} \mathrm{~kg}^{-1}\right)$ in all three cores and all depths $(\mathrm{cm})$ that were measured. Horizontal

806 error bars indicate propagated errors for excess ${ }^{210} \mathrm{~Pb}$. Measurements without horizontal error bars

807 were measured below detection limit. Vertical error bars represent the thickness of the measured

808 layer. 
809 Fig. 6: ${ }^{137} \mathrm{Cs}\left(\mathrm{Bq} \mathrm{kg}^{-1}\right)$ in all three cores and all depths $(\mathrm{cm})$ that were measured. Horizontal error

810 bars indicate measurement errors of ${ }^{137} \mathrm{Cs}$. Vertical error bars represent the thickness of the

811 measured layer.

812 Fig. 7: Marsh sedimentation rates from 1938-2003 ( $\left.\mathrm{mm} \mathrm{yr}^{-1}\right)$. Horizontal error bars represent the

813 averaged uncertainty of the ${ }^{210} \mathrm{~Pb}$ dating.

814 Fig. 8: Hydrological data from 1938-2007 at tide gauge Hörnum Hafen (Sylt). Storm intensity

815 (stars), mean tidal high water (MHW), mean sea level (MSL), and mean tidal low water (MLW)

816 are given in meter above 'Normal Null' (NN). A 19-years running mean is given for MHW, MSL,

817 and MLW. Storm frequency (bars) is the number of storm events that exceeded the level of $2.4 \mathrm{~m}$

818 above NN. Source: Wahl 2010, Hartwig 2010.

819 Fig. 9: Historic marsh elevations for all three cores derived from ${ }^{210} \mathrm{~Pb}$ and ${ }^{137} \mathrm{Cs}$ data. Due to

820 several data points below the detection limit in core S1, two graphs are displayed, comparing the

821 fastest possible accretion rates (open circles) with the slowest possible accretion rates (filled

822 circles). For validation of the data, the ${ }^{137}$ Cs peaks are included (open diamonds). The error bars

823 (as shown in figure 6) were omitted for clarity. The mean high water and the mean sea level

824 (MHW and MSL: solid lines) are displayed as 5-years running averages.

825 Fig. 10: Comparison of sedimentation rates (stars) at core location S2 with storm intensity (open 826 circles), defined as the mean height for all high water levels exceeding $1.34 \mathrm{~m}$ (NN).

827 Fig. 11: Comparison of sedimentation rates (stars) at core location S2 with storm frequency (open 828 circles), defined as the number of water levels, exceeding $2.4 \mathrm{~m}(\mathrm{NN})$.

829 Fig. 12: Results of linear regression analysis: $\beta$ - and p-values (circles and triangles respectively)

830 for different storm water levels ( $m$ above $\mathrm{NN}$ ) are shown. $\beta$ - and p-values refer to results of

831 multiple linear regression analyses of storm frequency (filled symbols) and storm intensity (open

832 symbols) with sedimentation rates at core location S2.

833 Fig. 13: Conceptual scheme of how vegetation is influencing accretion rates at various storm water

834 levels. The "No vegetation scenario" does not reflect the resuspension happening in absence of a 835 vegetation canopy. 


\section{FIGURES}

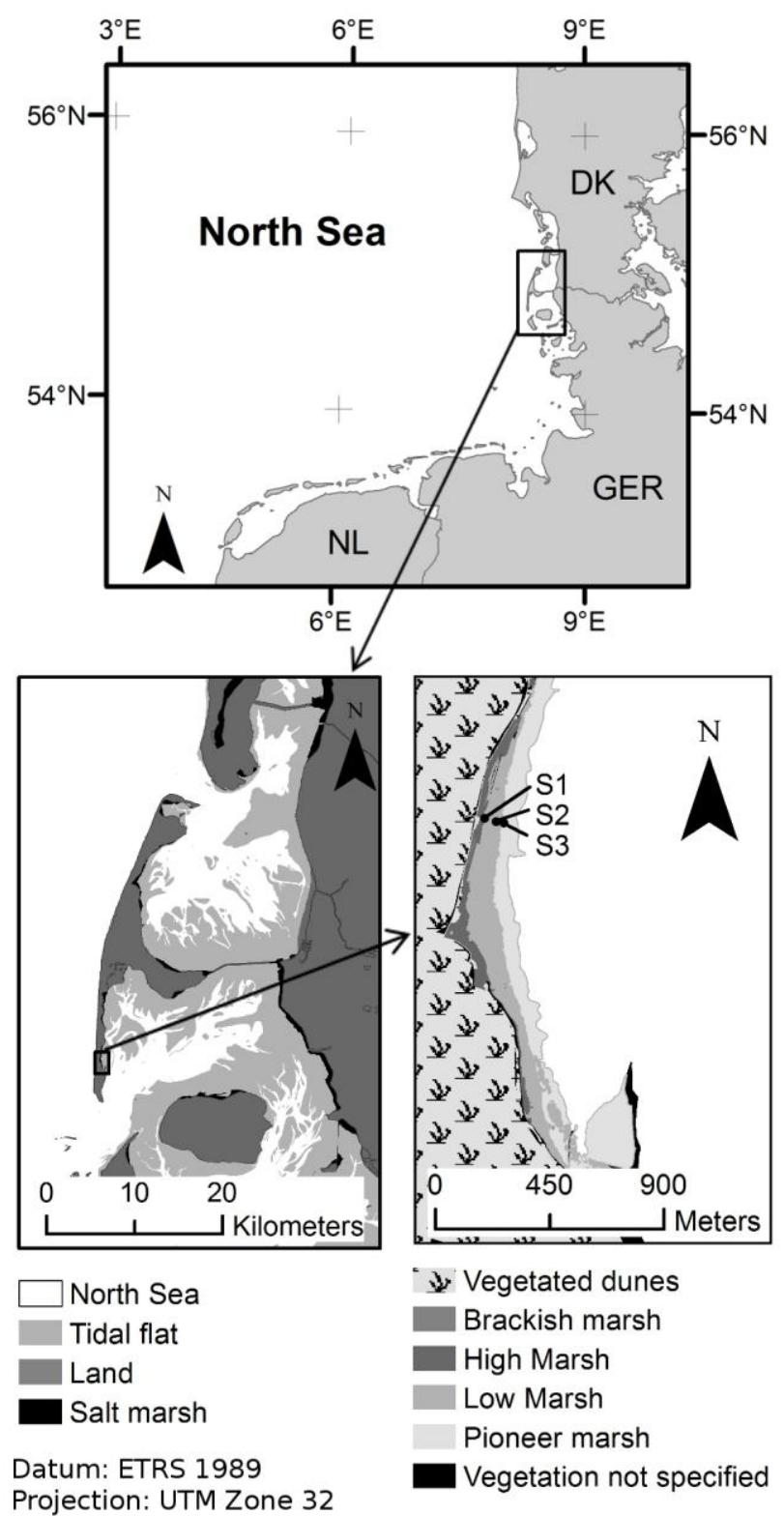

837

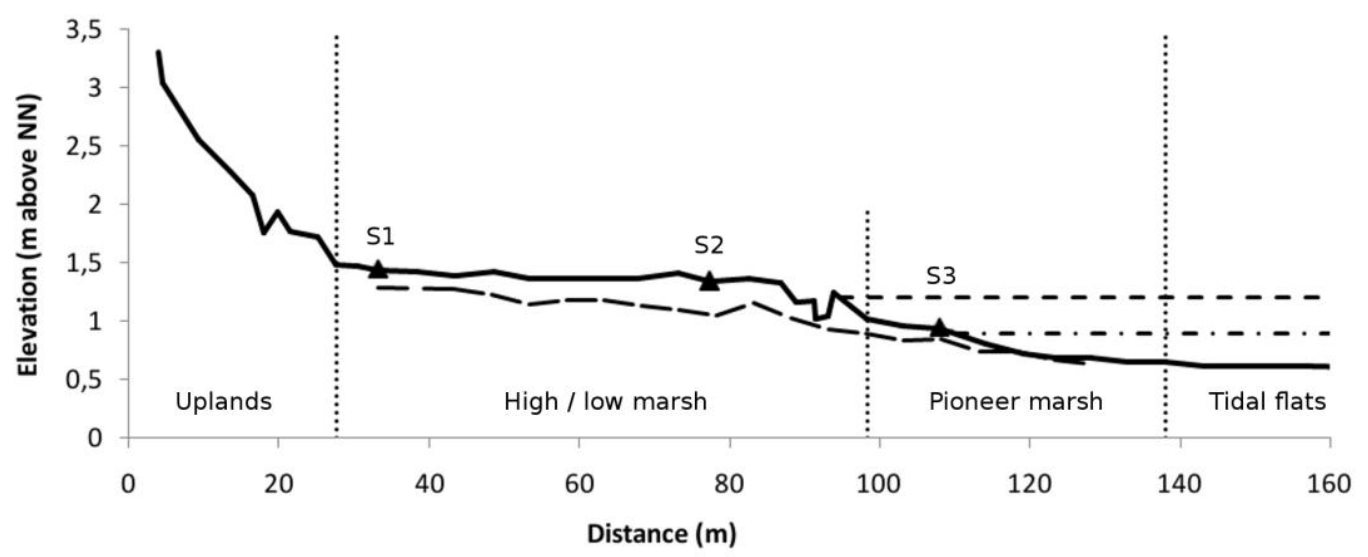




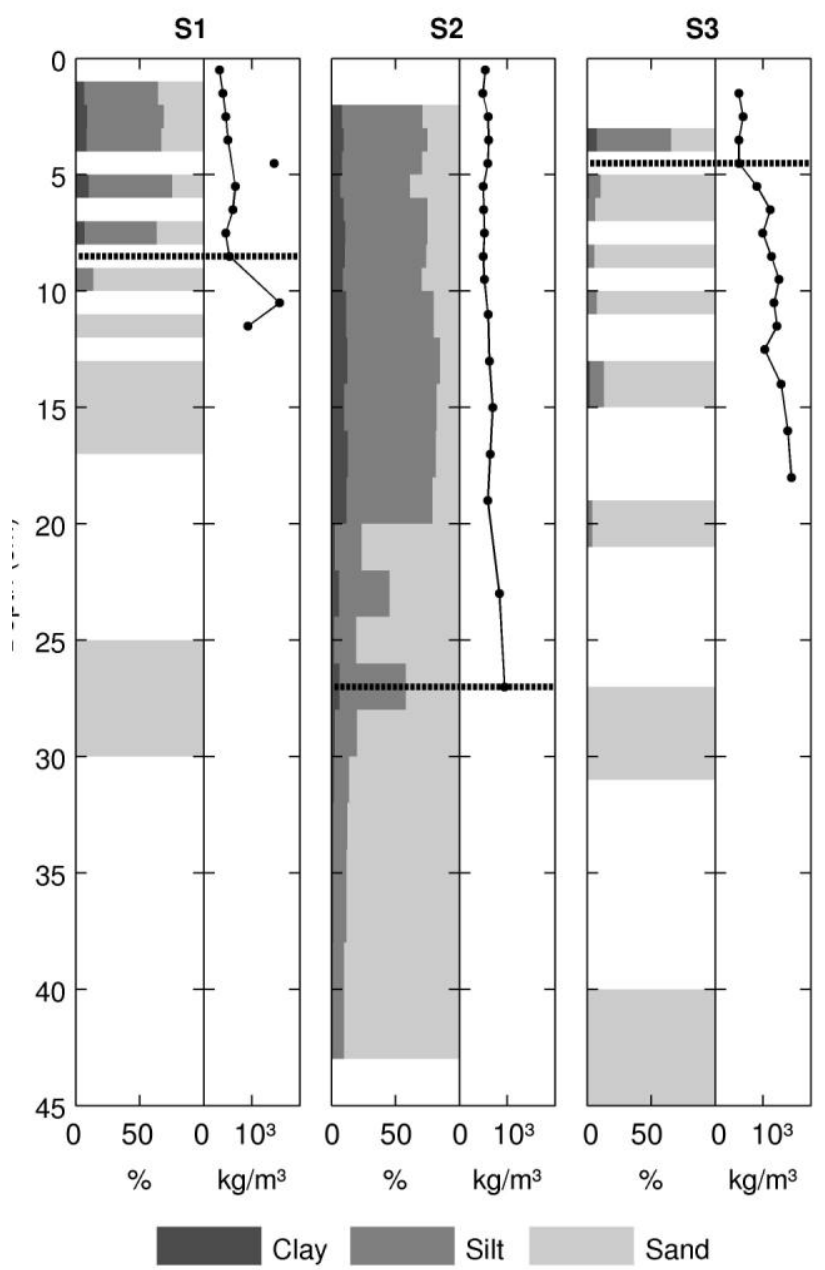




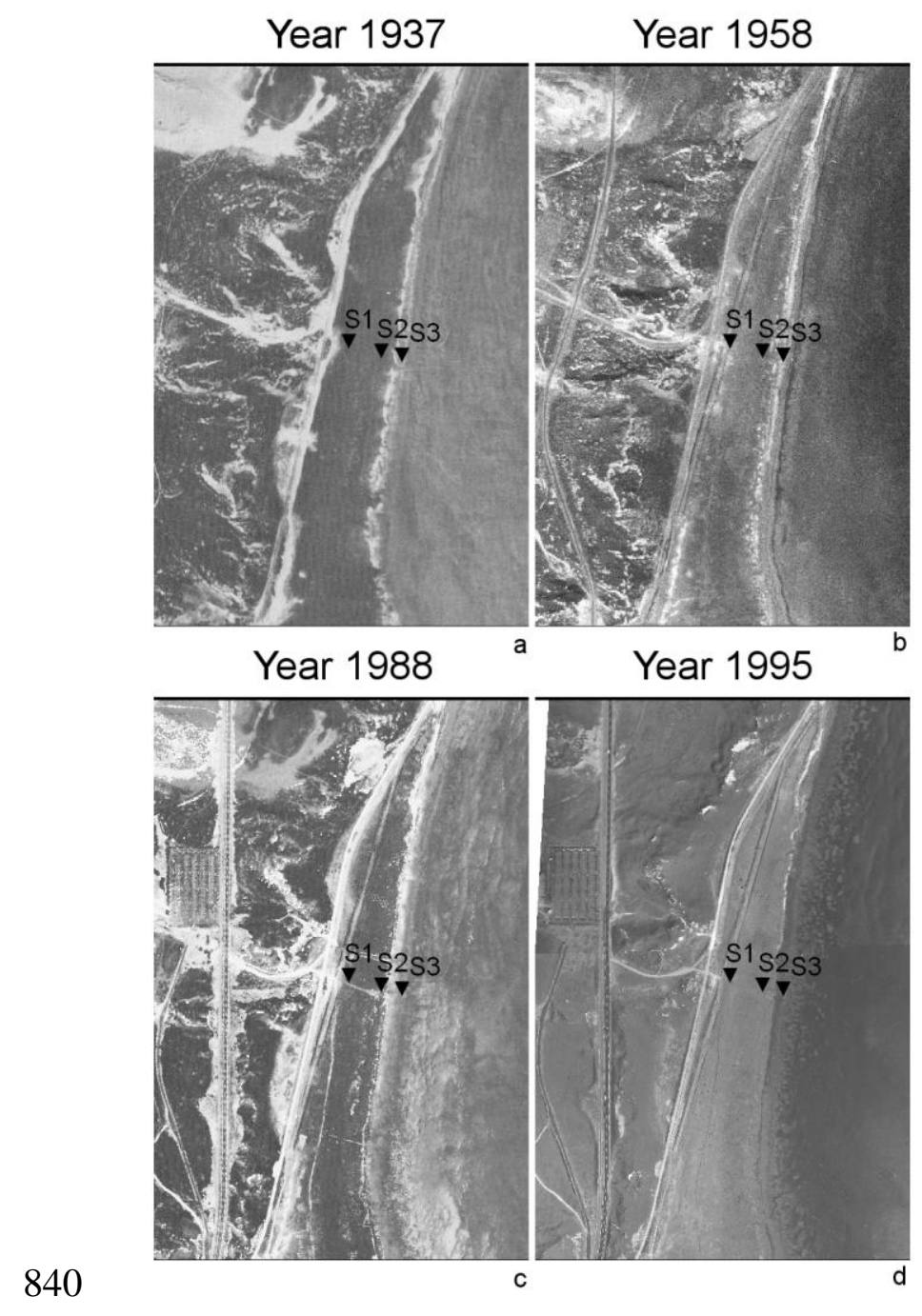



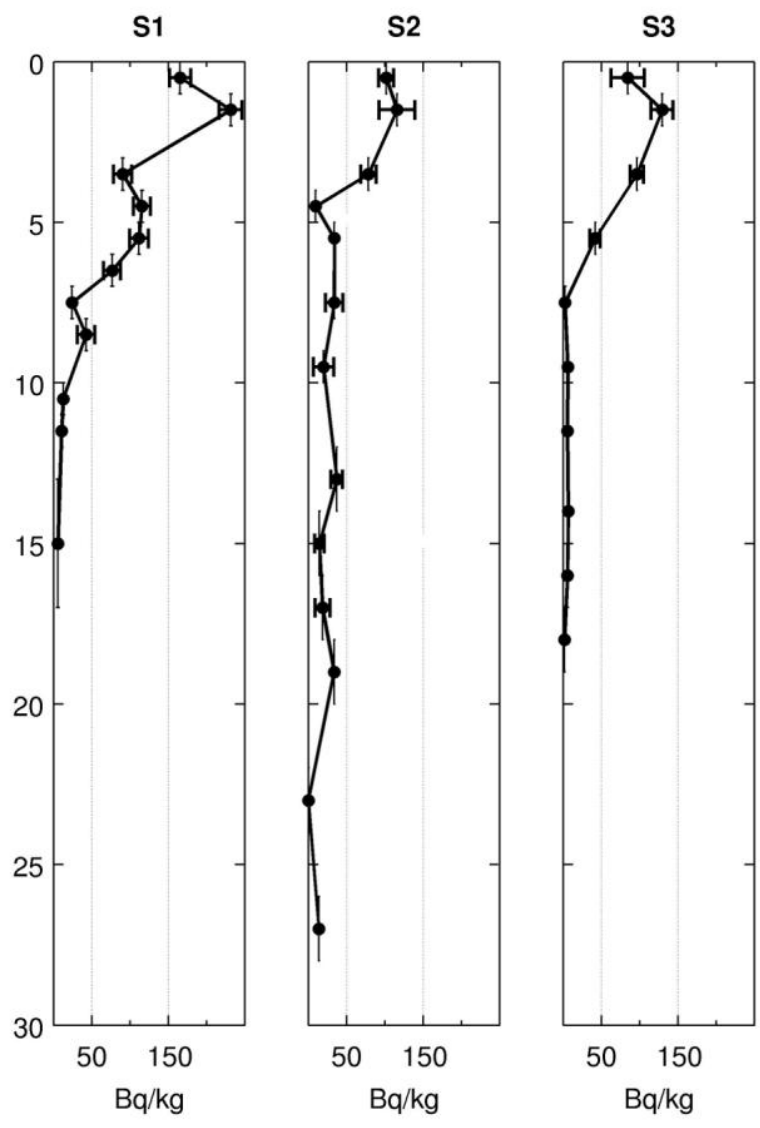

841

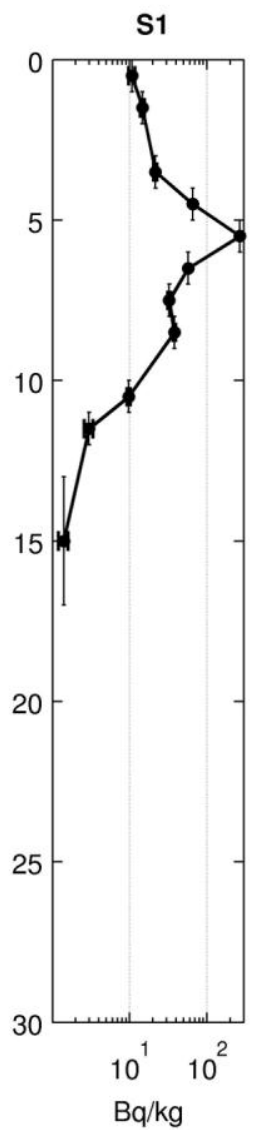

$\longrightarrow$ Excess 210Pb

S2

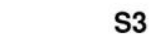

842
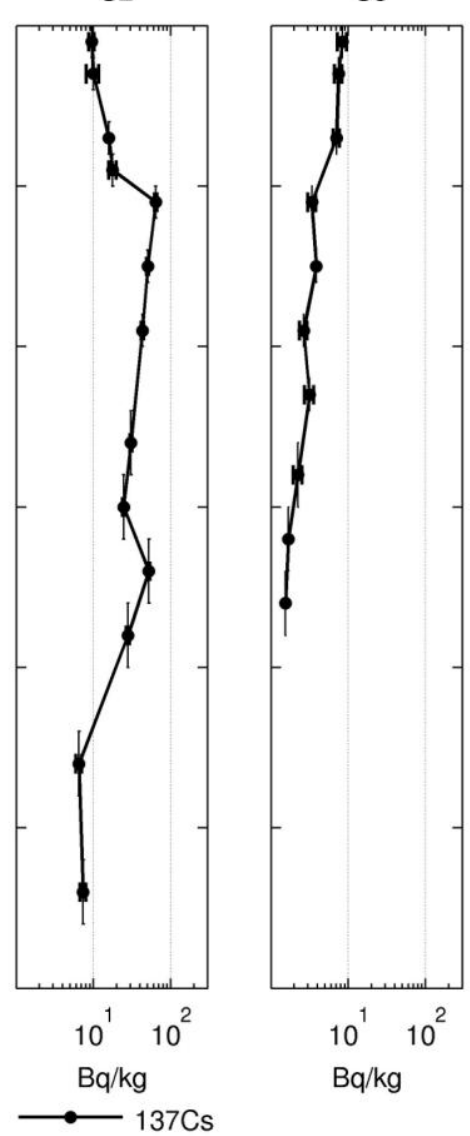
843

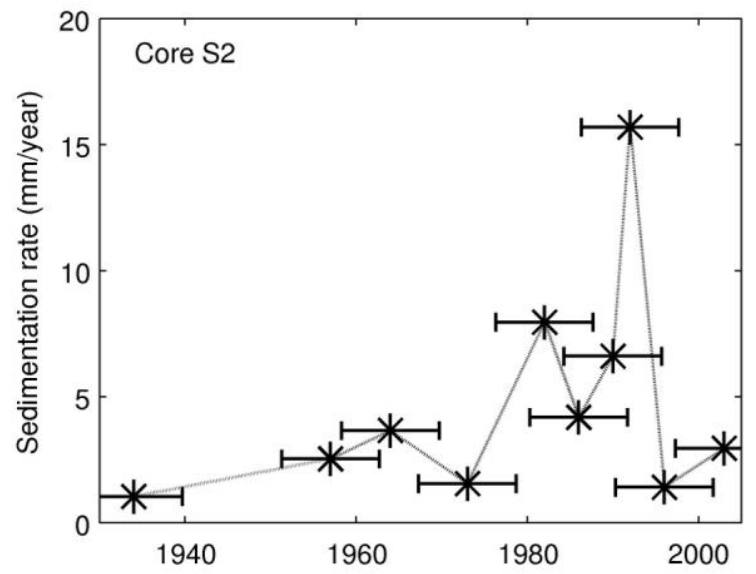

844

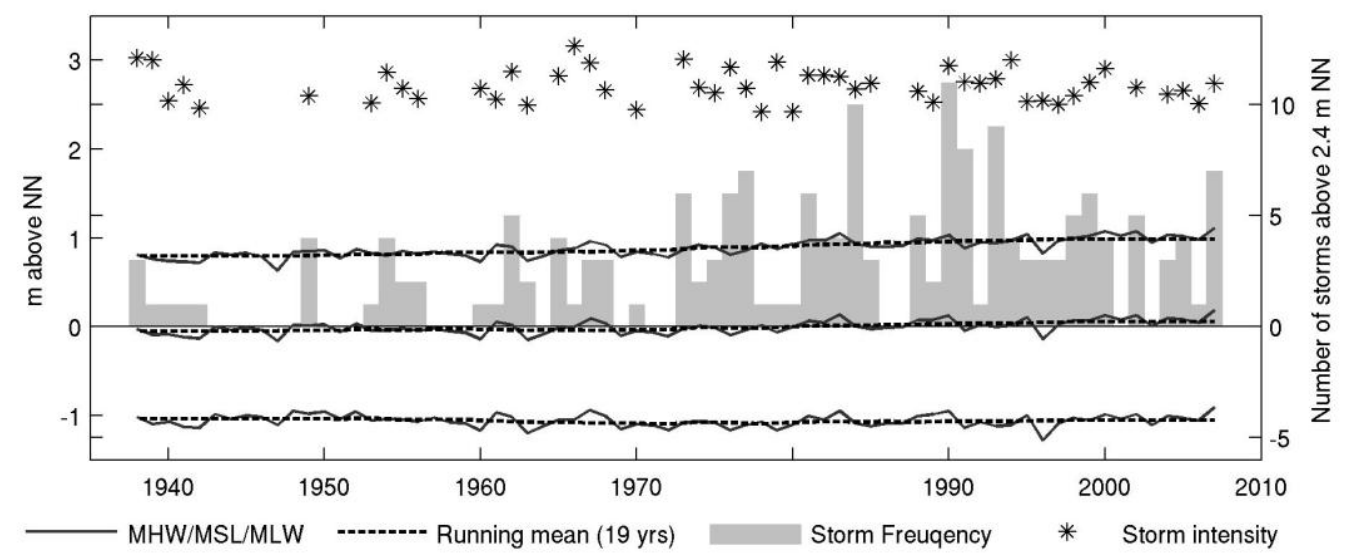

845
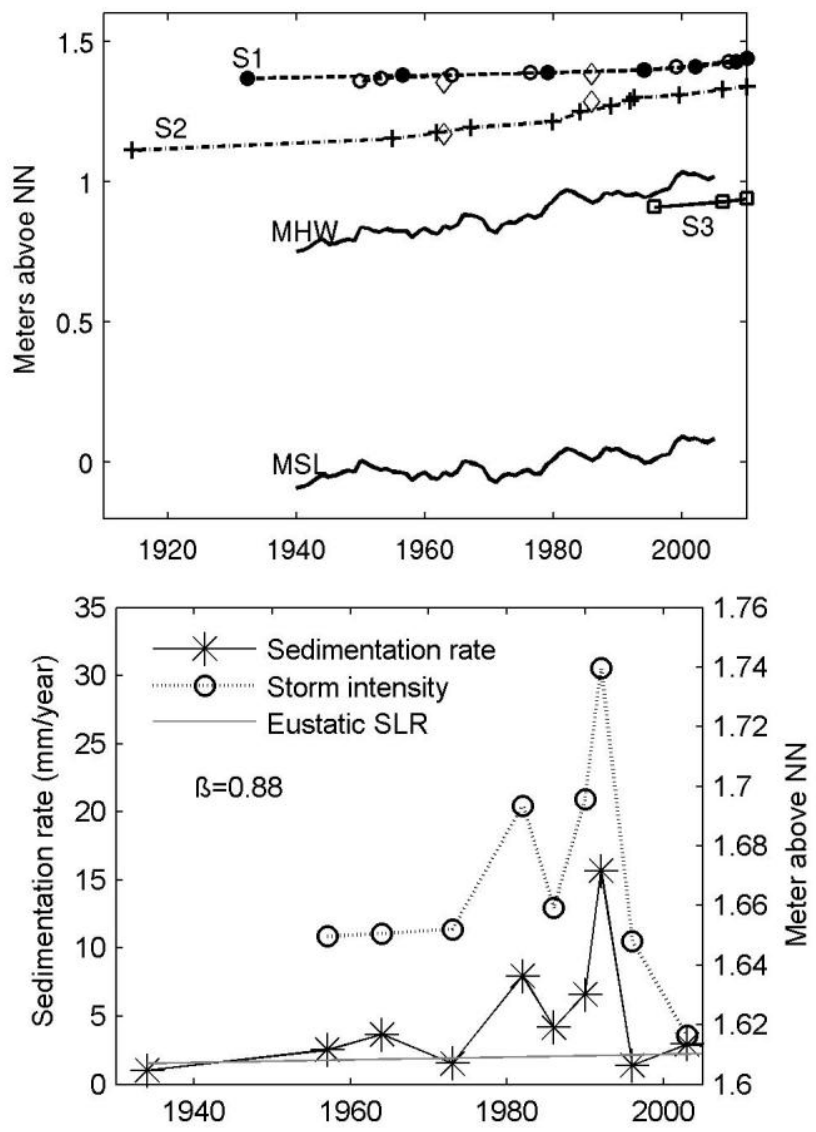


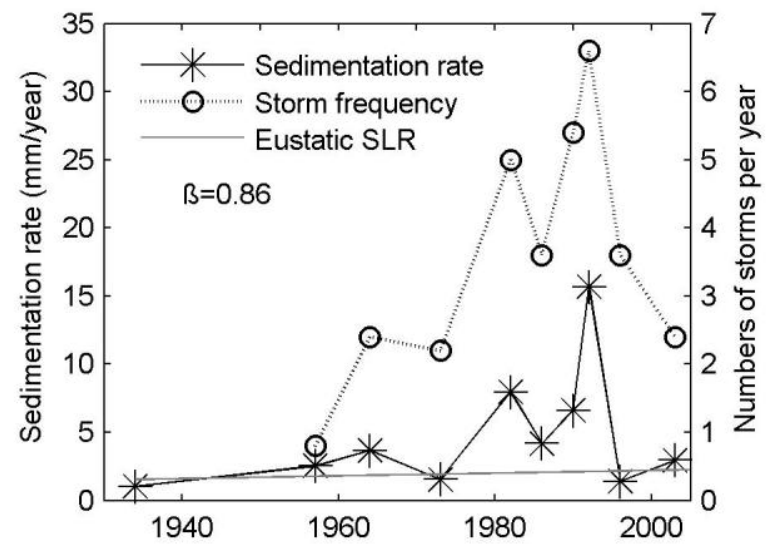

847

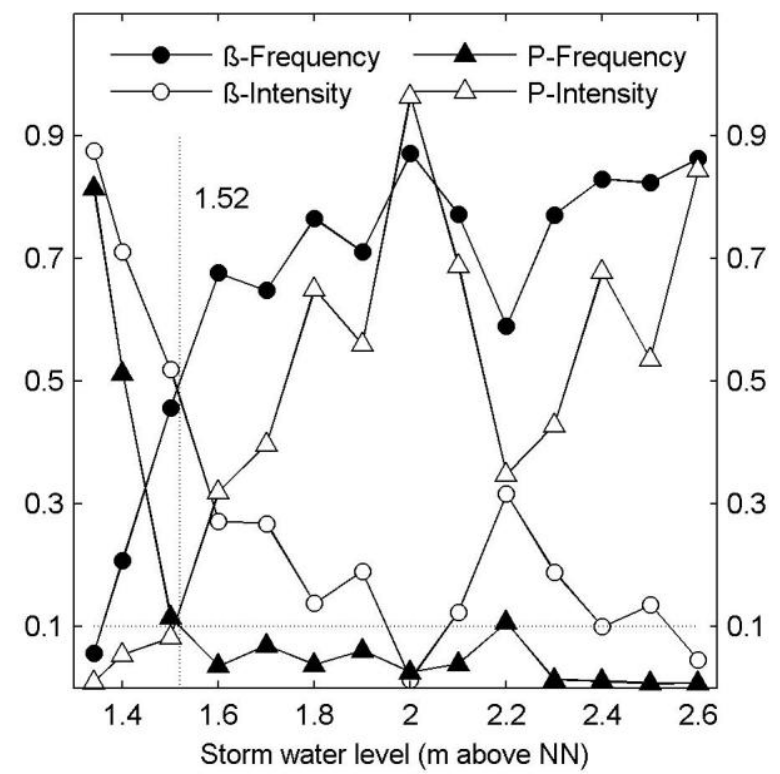

848

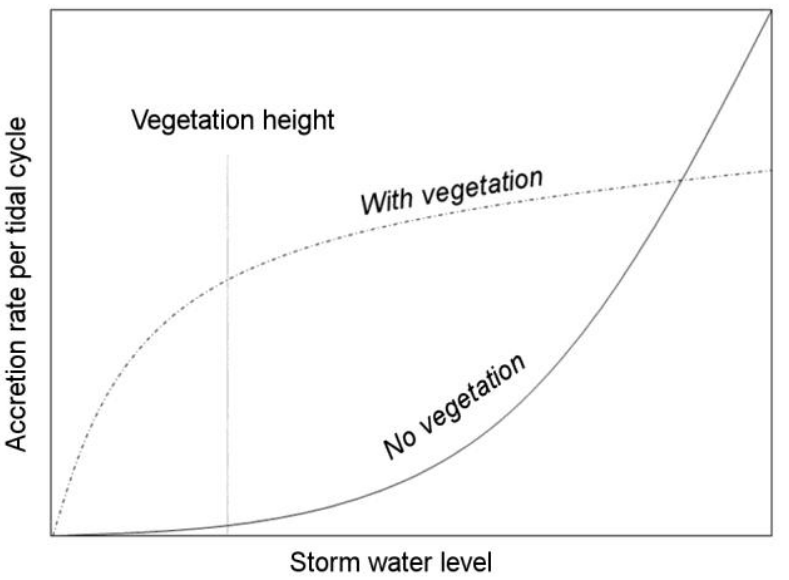



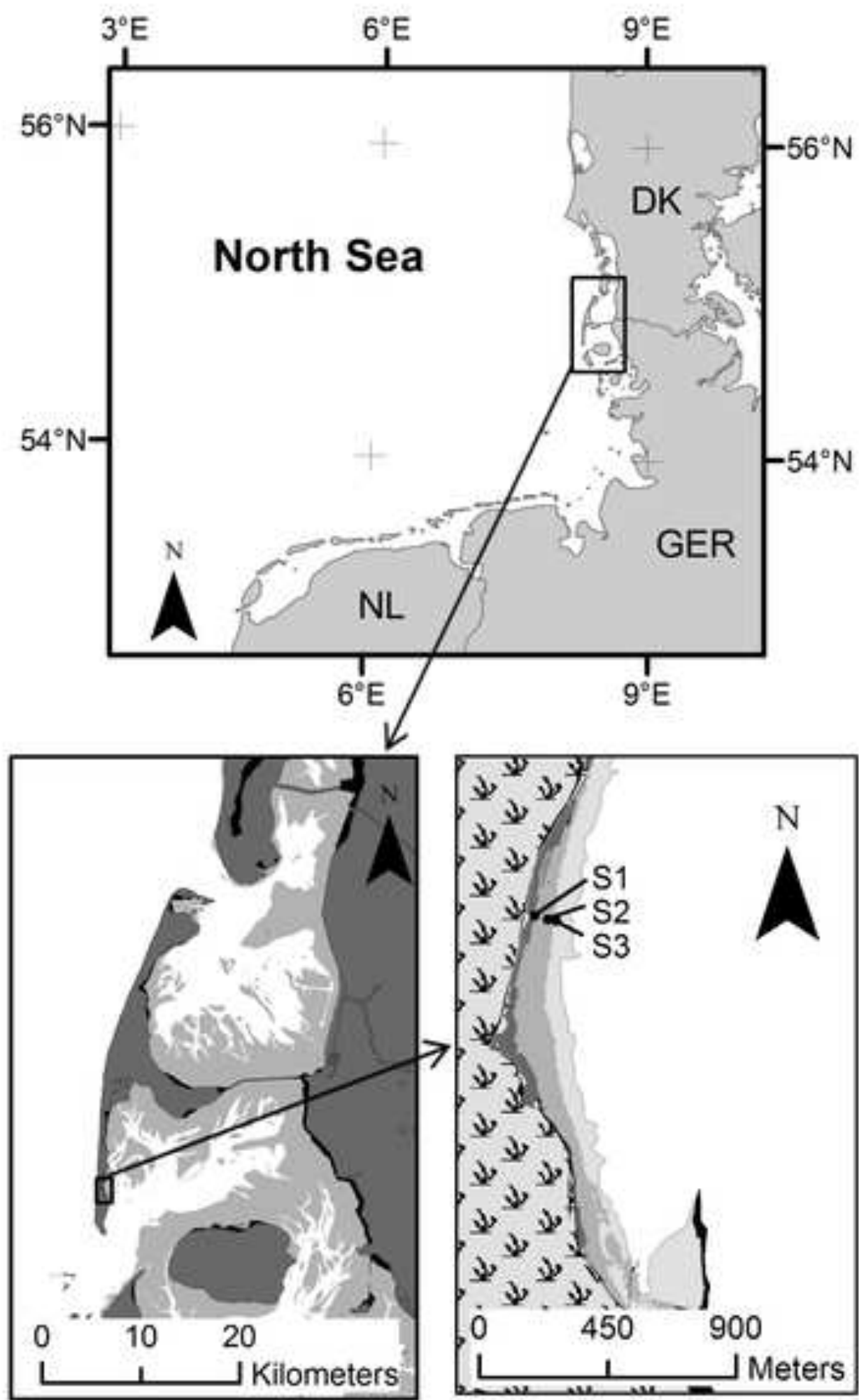

$\square$ North Sea

- Tidal flat

Eland

Salt marsh

Datum: ETRS 1989

Projection: UTM Zone 32 iv Vegetated dunes

Brackish marsh

High Marsh

Low Marsh

Pioneer marsh

Vegetation not specified 


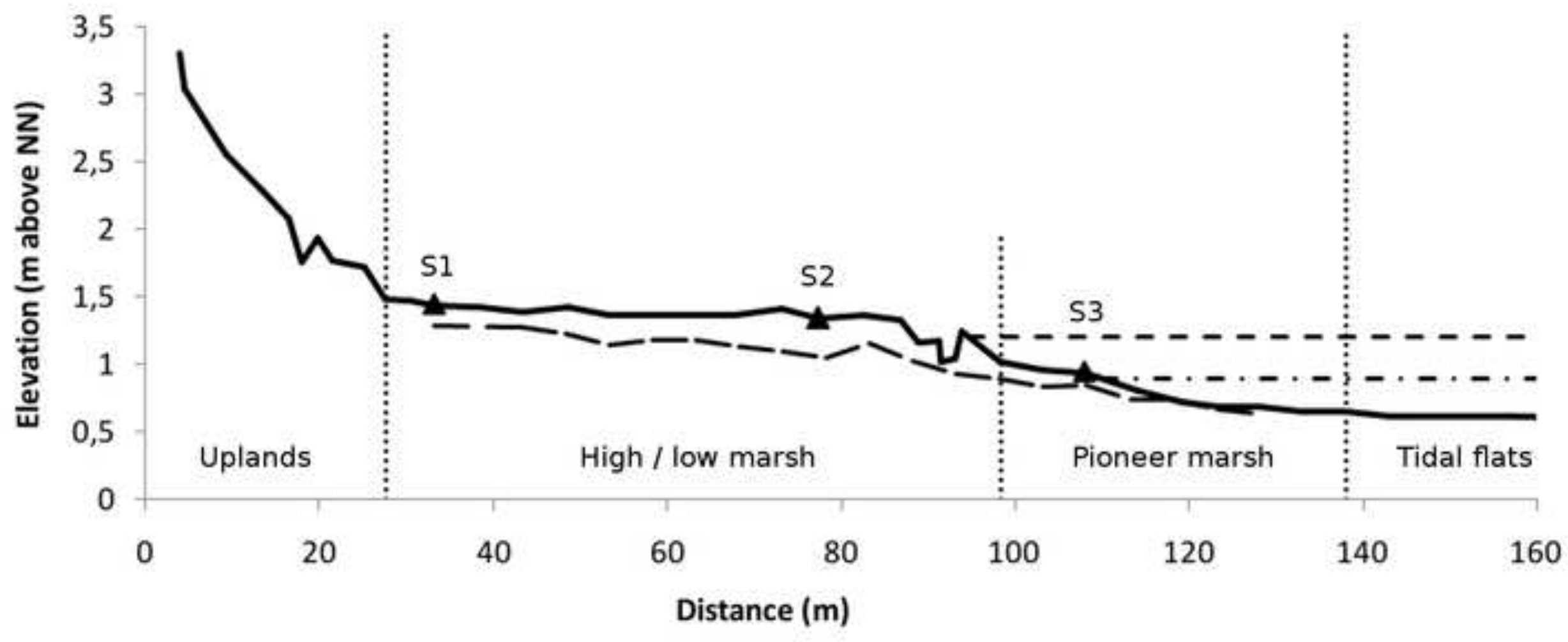




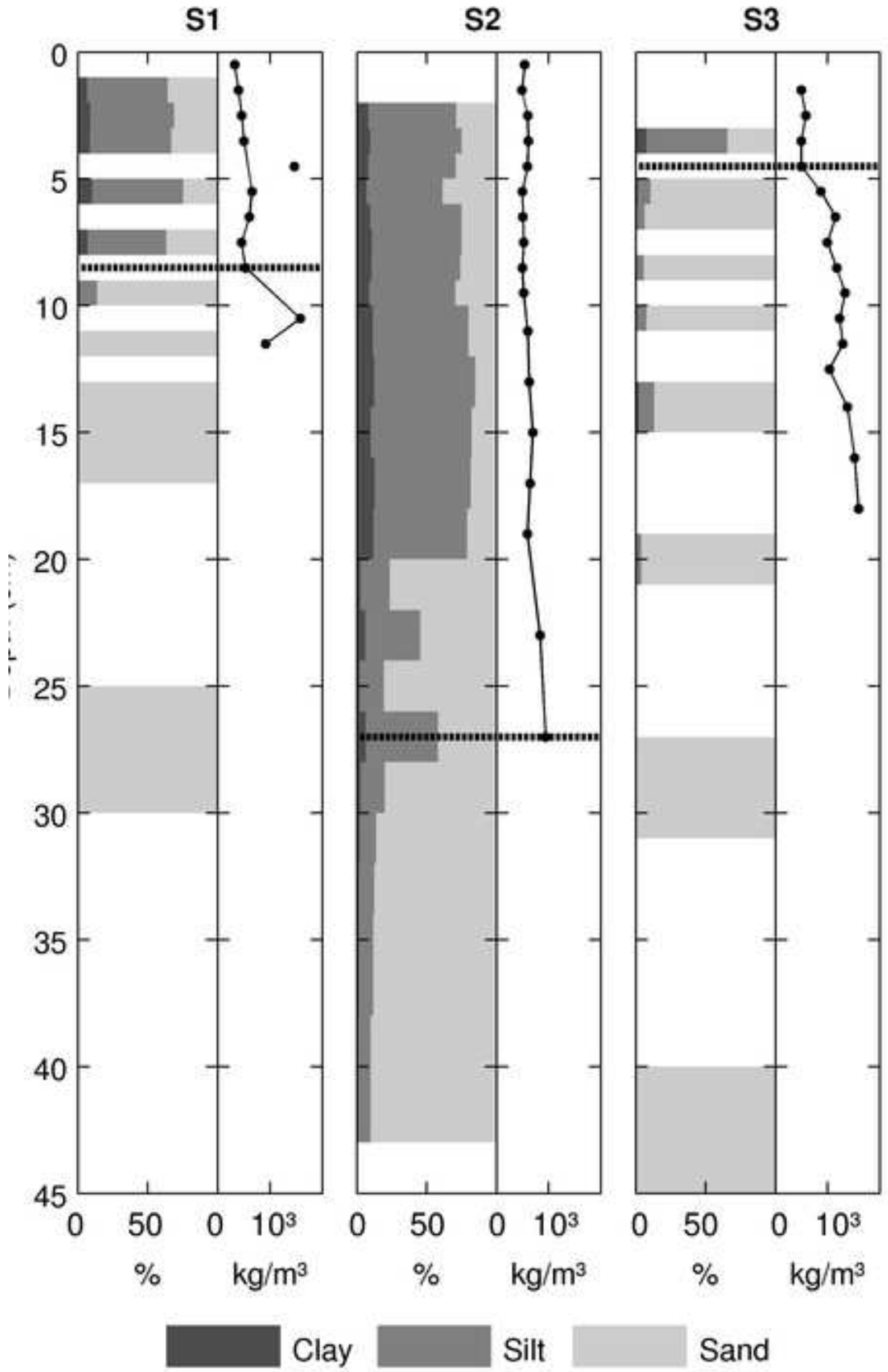


Figure 4

Click here to download high resolution image
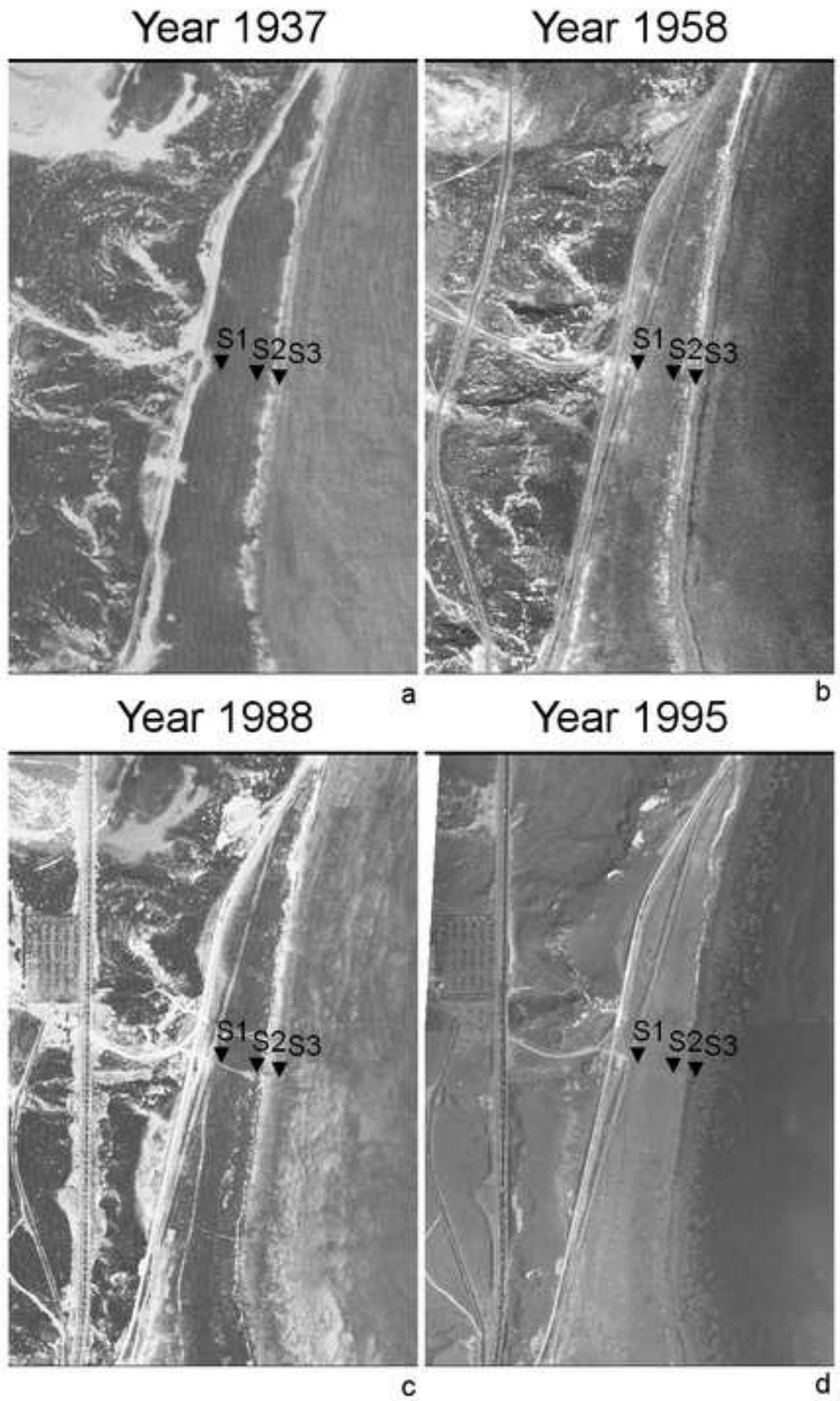
Figure 5

Click here to download high resolution image

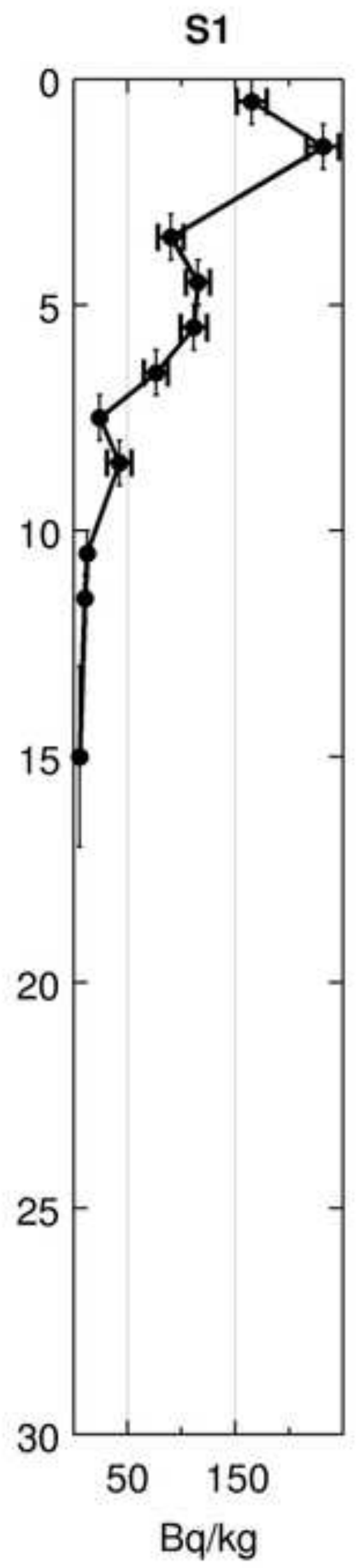

S2

S3
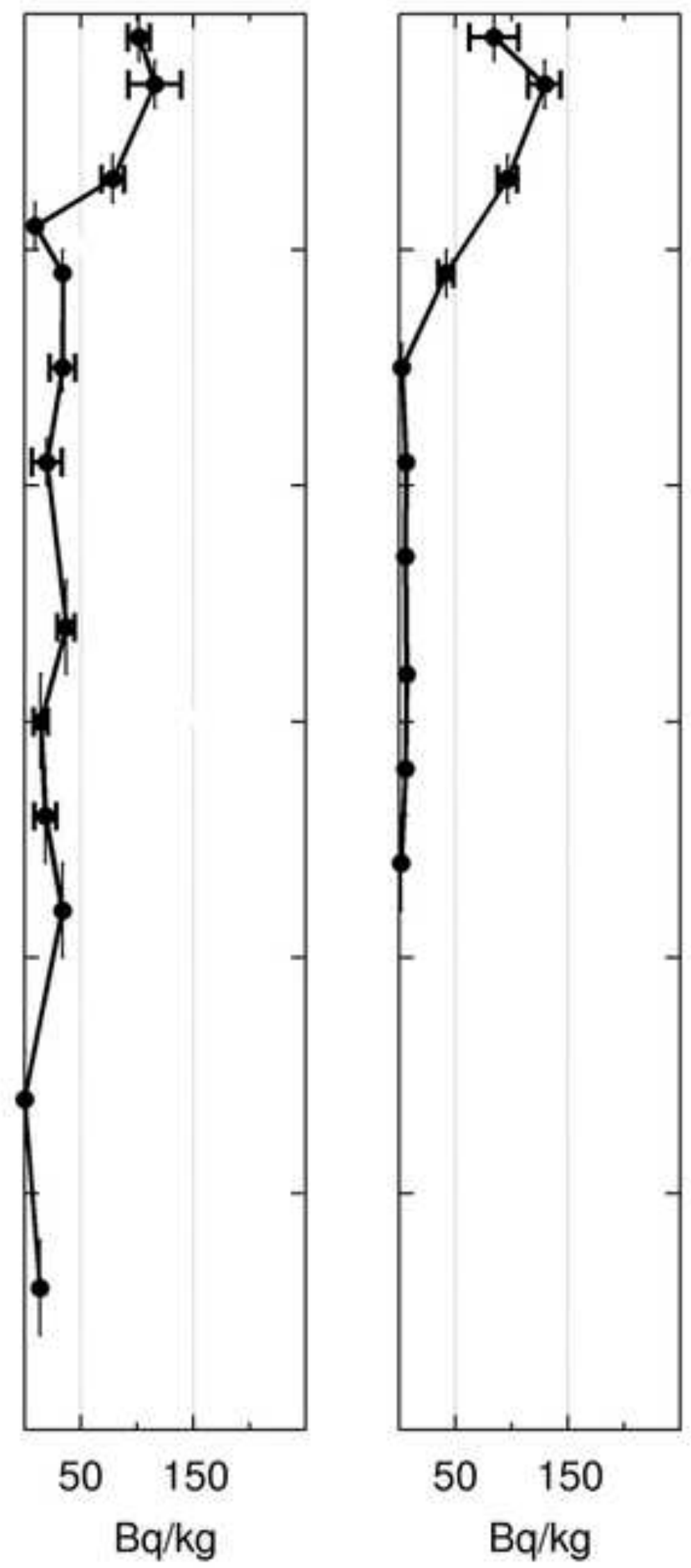

Excess $210 \mathrm{~Pb}$ 
S1

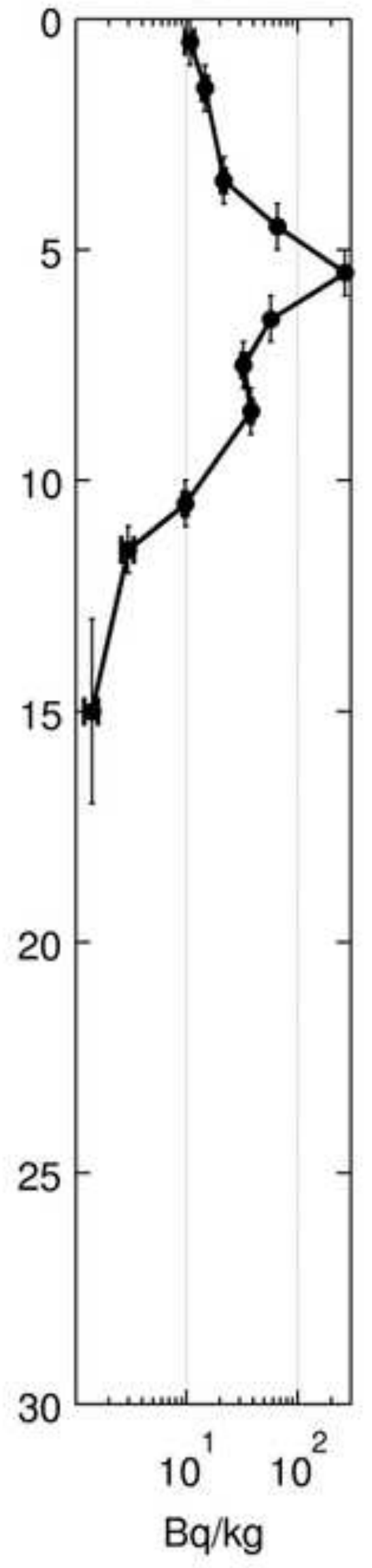

S2

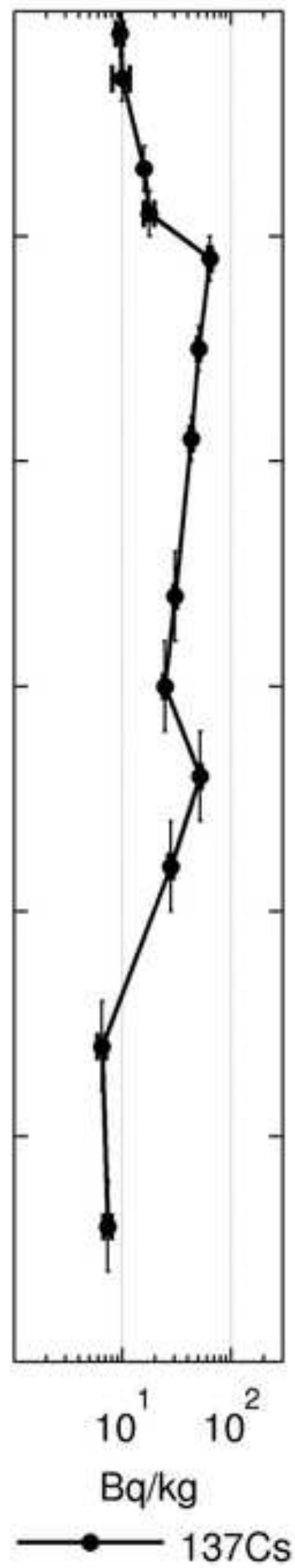

S3

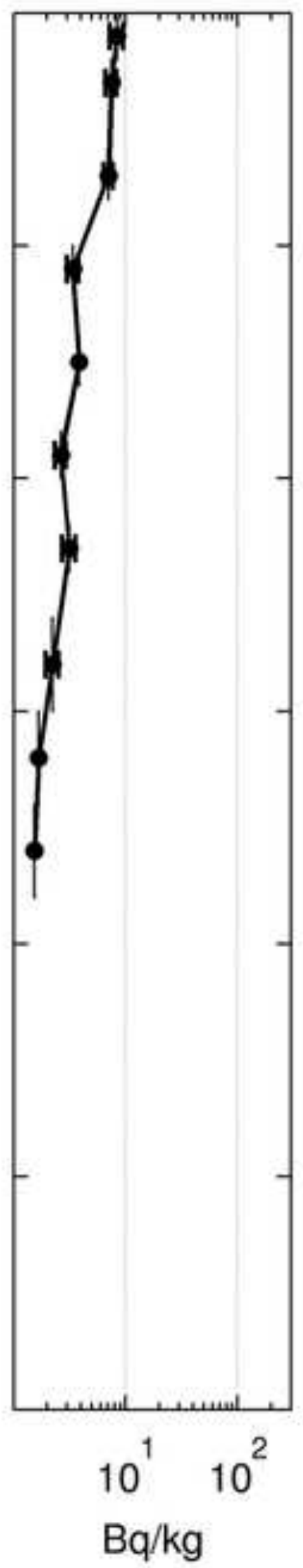

$$
\text { s }
$$


Click here to download high resolution image

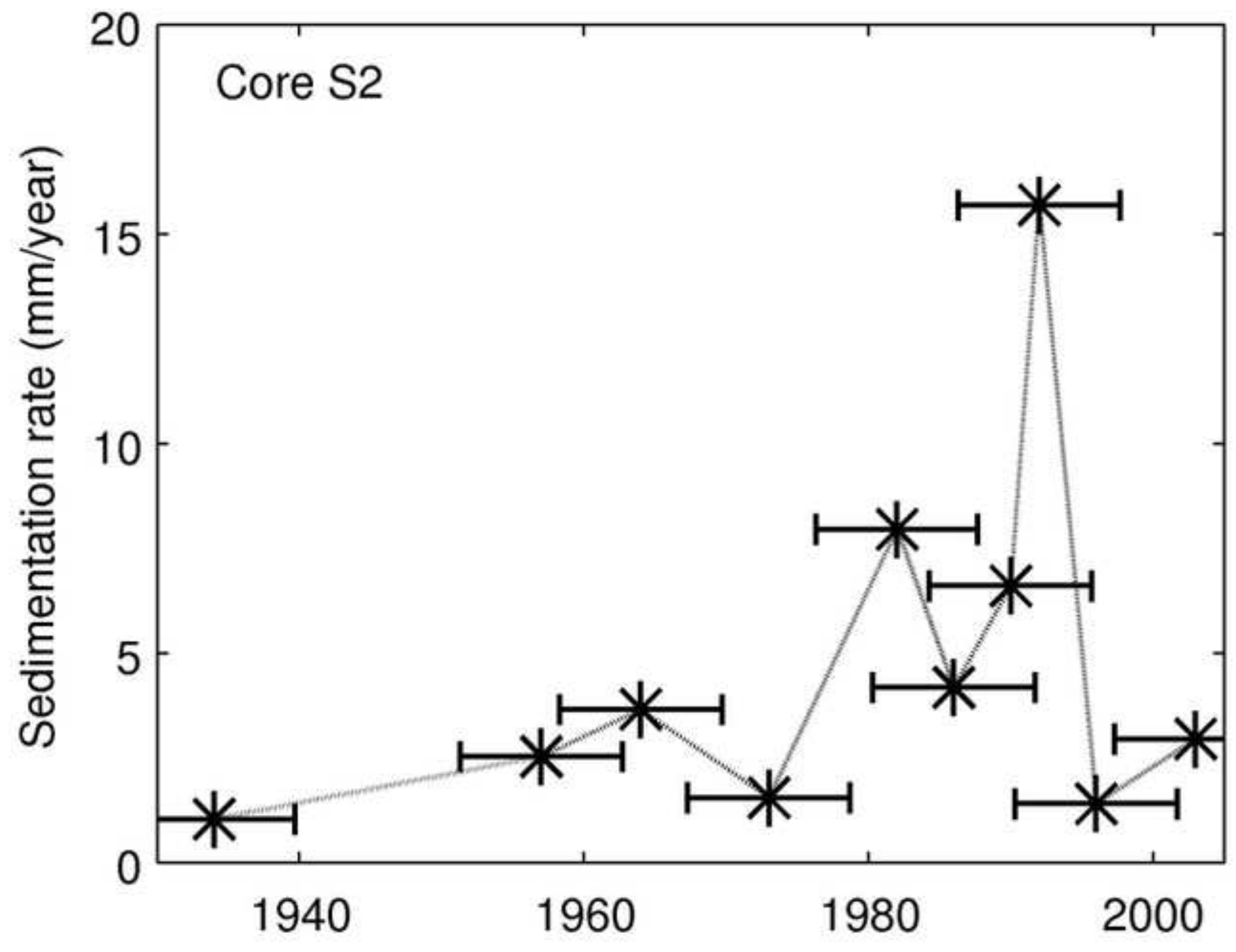




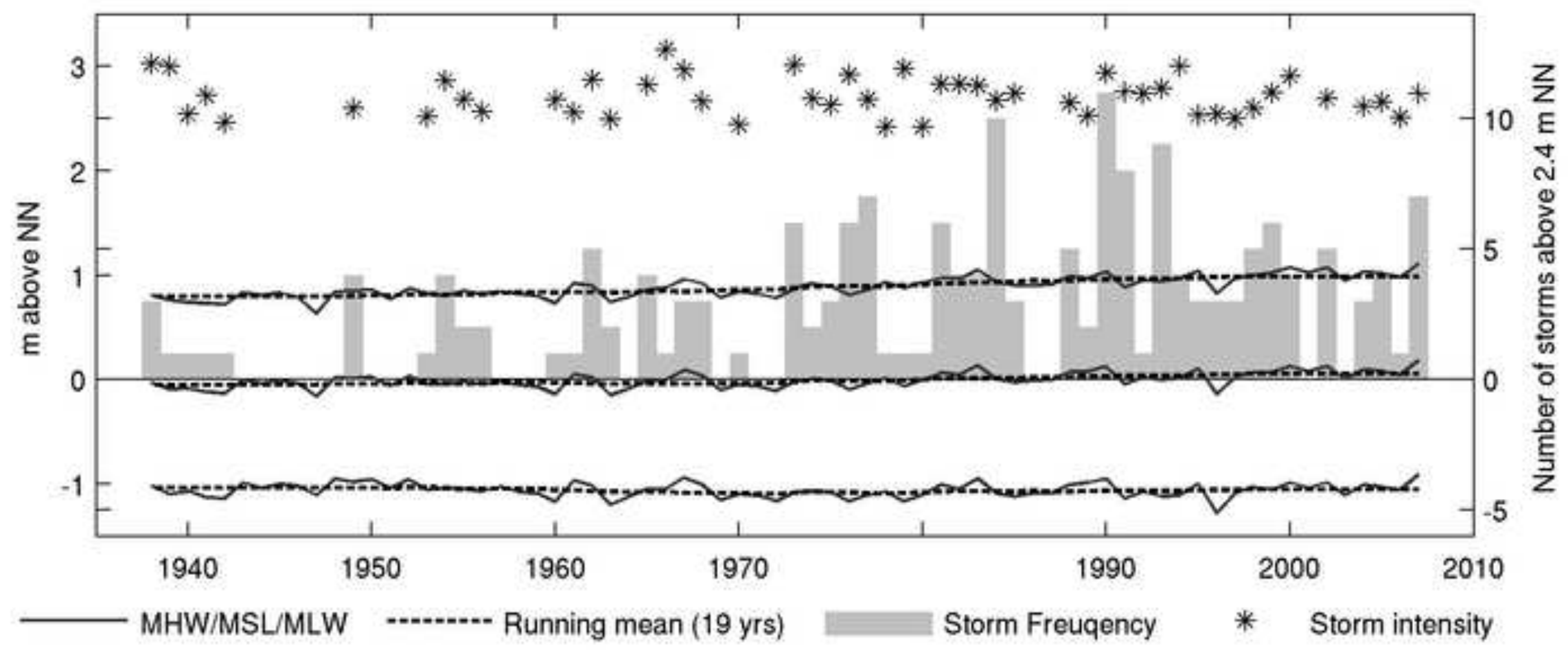




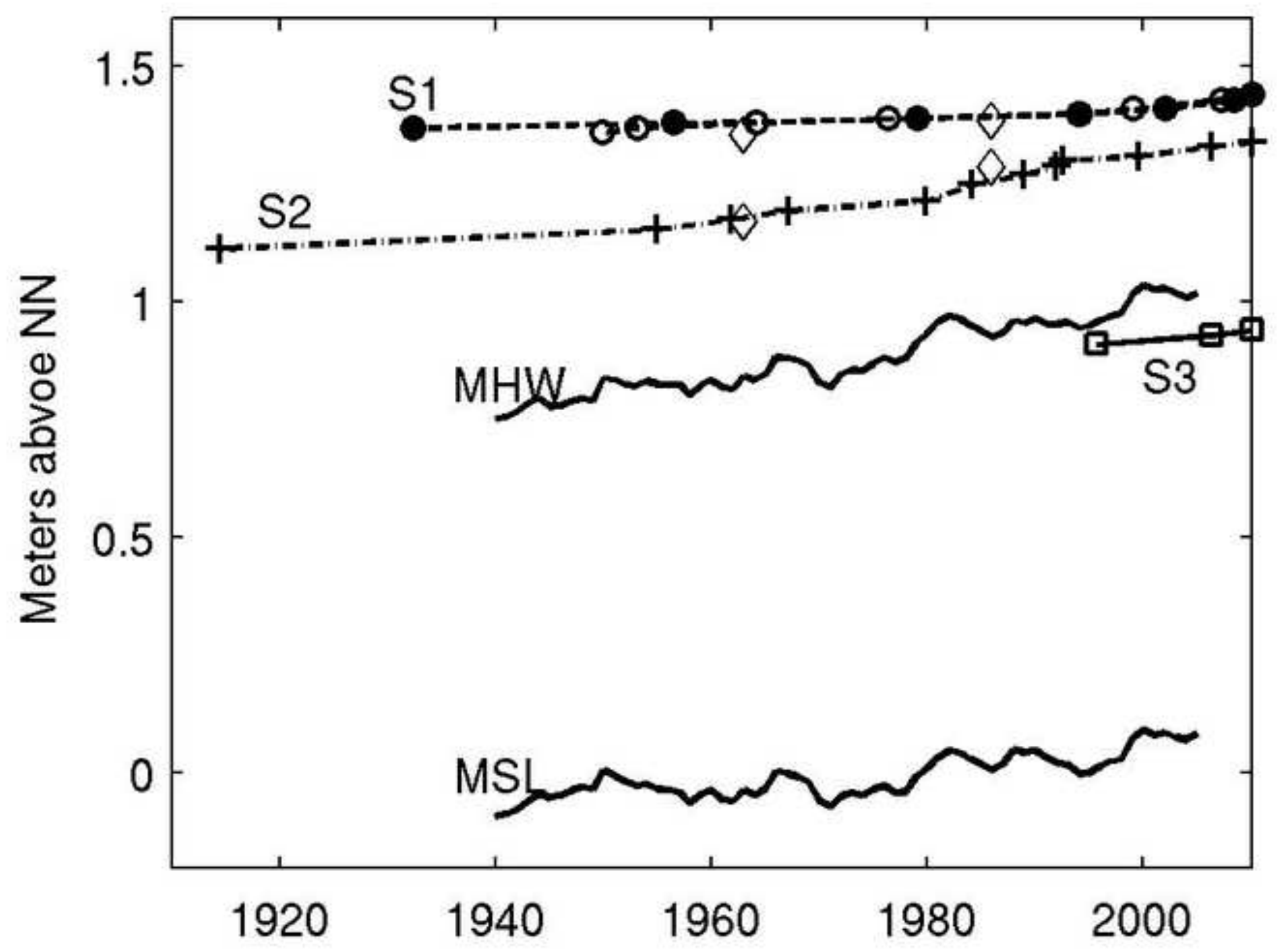




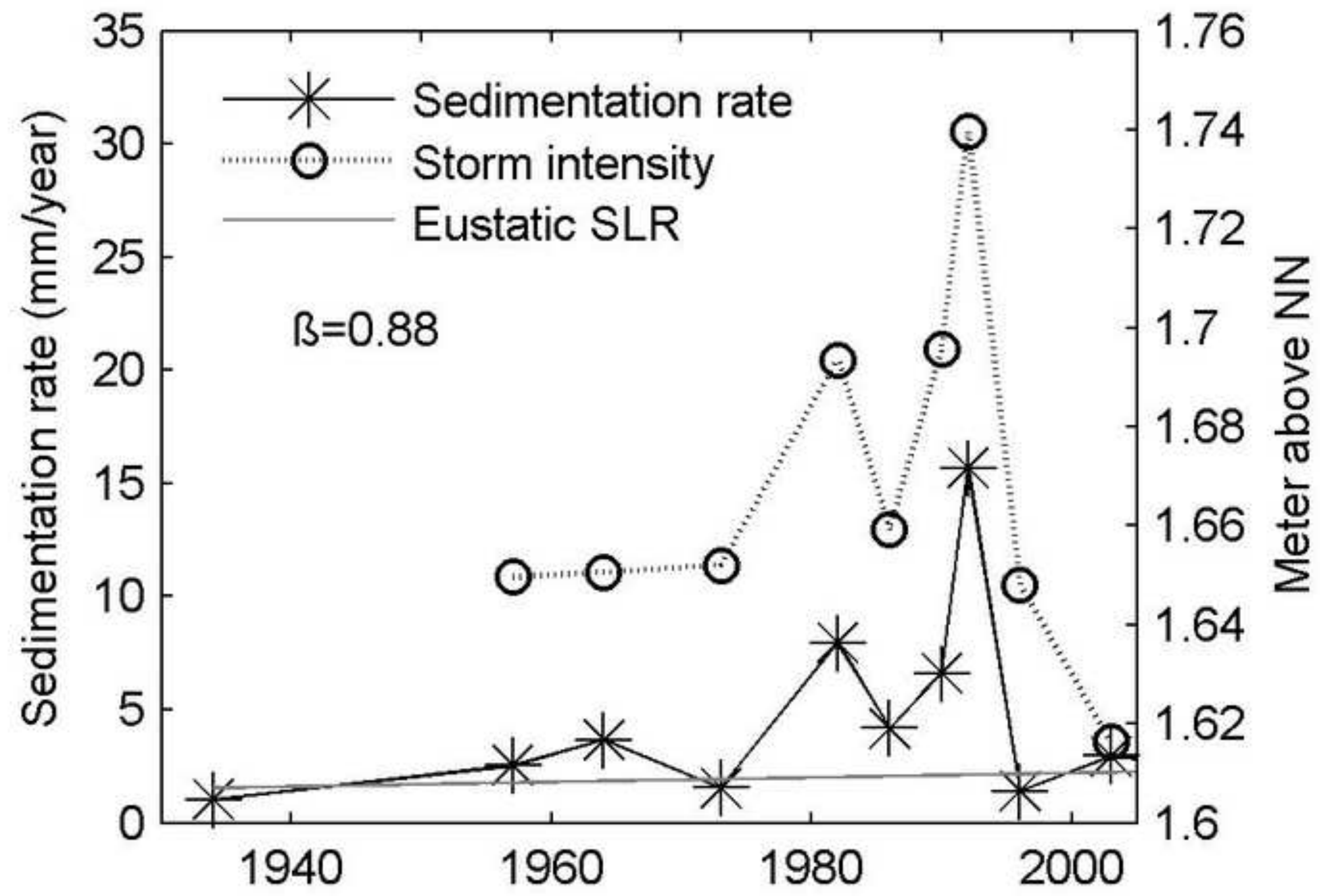




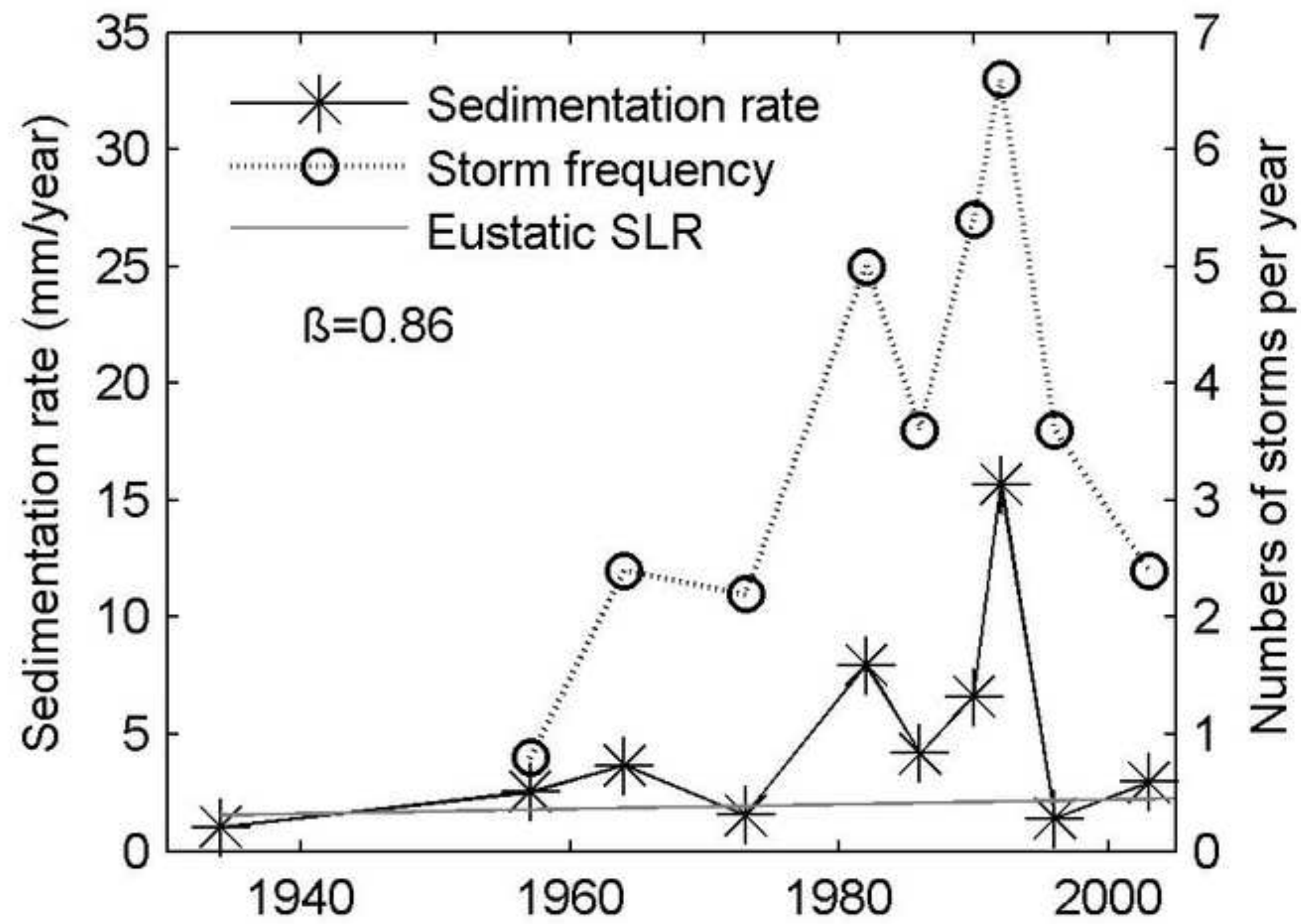




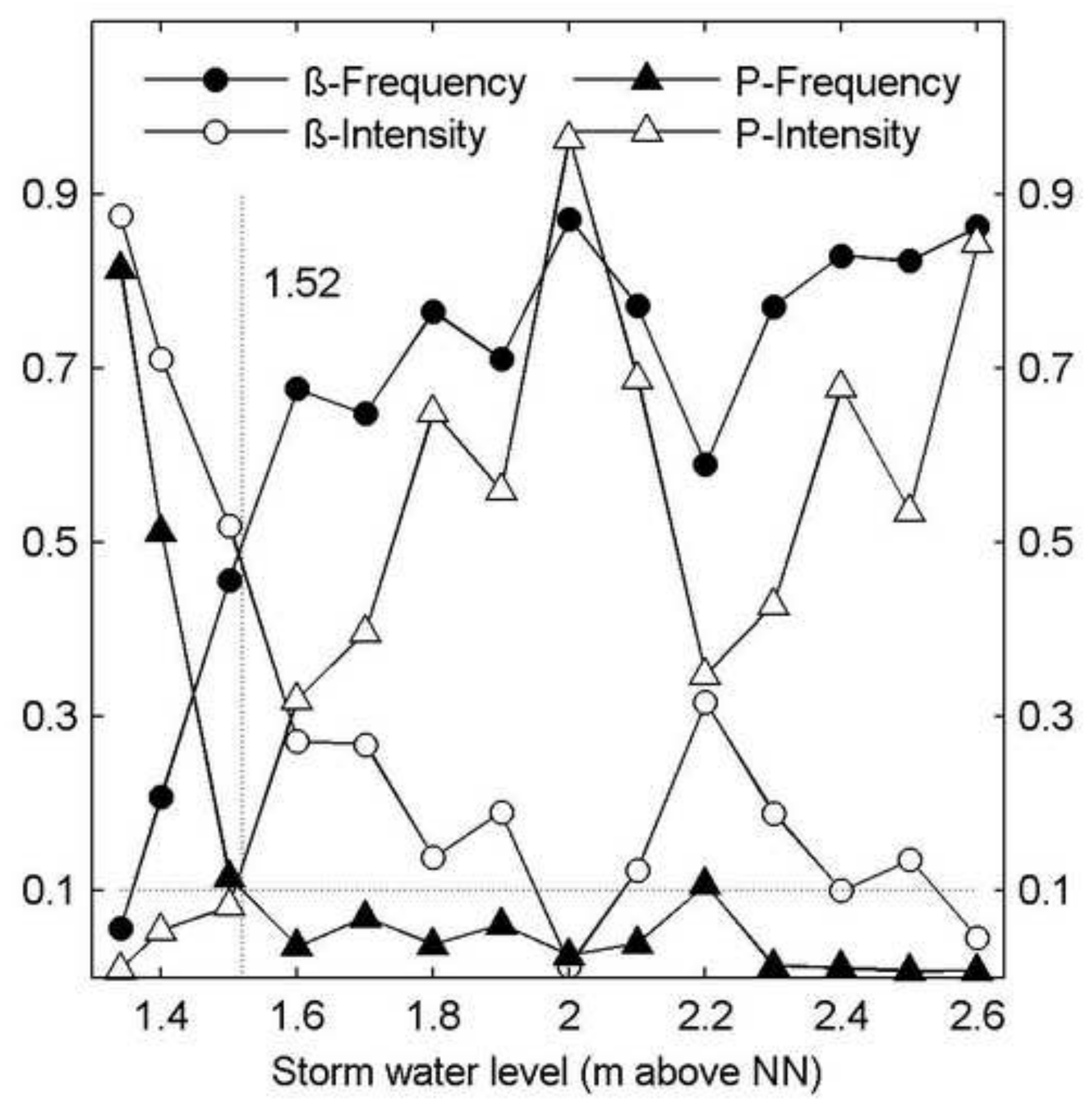




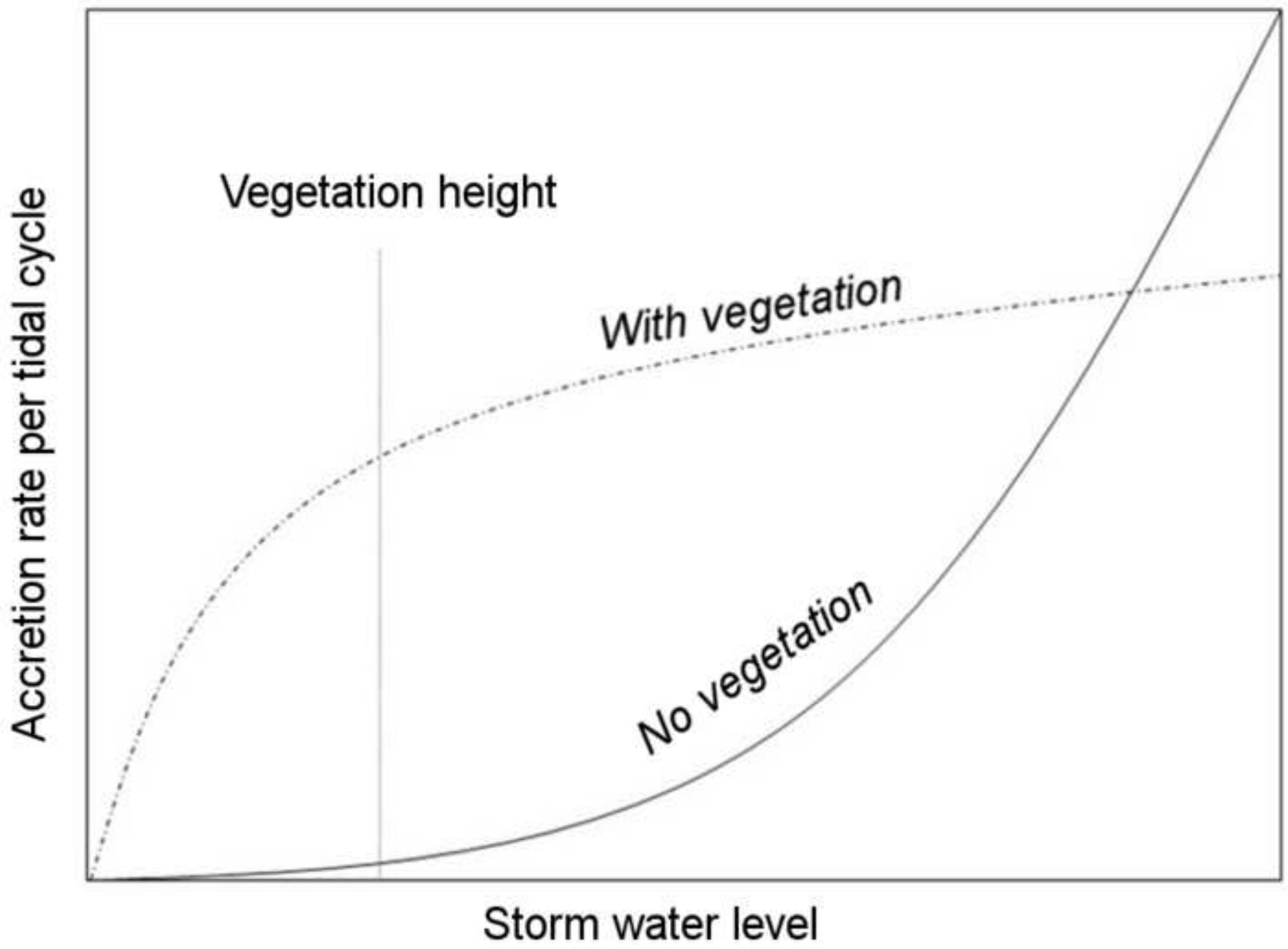


Table 1: Ages of base layers and mean sedimentation rates: Comparison of ${ }^{210} \mathrm{~Pb}$ datings with information from aerial photographs.

\begin{tabular}{|l|l|l|l|l|}
\hline $\begin{array}{l}\text { Core } \\
\text { name }\end{array}$ & $\begin{array}{l}\text { Depth of base } \\
\text { layer }\end{array}$ & $\begin{array}{l}\text { Age of base layer } \\
\left.\mathbf{(}^{\mathbf{2 1 0}} \mathbf{P b}\right)\end{array}$ & $\begin{array}{l}\text { Age of base layer (aerial } \\
\text { photographs) }\end{array}$ & $\begin{array}{l}\text { Sedimentation rate } \\
\text { (mm/year) }\end{array}$ \\
\hline S1 & $8.5 \mathrm{~cm}$ & $1925-1955$ & $<1937$ & $1-1.2$ \\
\hline S2 & $>27$ & 1915 & $<1937$ & 2.8 \\
\hline S3 & $4.5 \mathrm{~cm}$ & $1978-1988$ & $1988-1995$ & 2.5 (since 1996) \\
\hline
\end{tabular}

